http://jmscr.igmpublication.org/home/ ISSN (e)-2347-176x ISSN (p) 2455-0450 crossref DOI: https://dx.doi.org/10.18535/jmscr/v9i4.23

Journal Of Medical Science And Clinical Research

\title{
Role of Advanced Magnetic Resonance Imaging Techniques in the Evaluation of Intracranial Masses and Mass like Lesions
}

\author{
Authors \\ Deba Kumar Chakrabartty ${ }^{1}$, Bhaskar Jyoti Pegu ${ }^{2}$, Atul Kumar Singh ${ }^{3}$ \\ ${ }^{1}$ Head of the department \\ ${ }^{2}$ Assistant professor \\ *Corresponding Author \\ Atul Kumar Singh
}

\section{Introduction}

Intracranial mass lesions are a broad and very disparate group of pathological conditions ranging from brain tumours to non-neoplastic conditions such as abscess or neurocysticercoses. Intracranial mass lesions are a significant health problem and present several imaging challenges and radiology has played an integral role in the diagnosis, monitoring, and treatment planning of intracranial masses. MRI in particular, offers superior softtissue contrast over other cross-sectional imaging techniques allowing for better visualisation of subtly infiltrated or disrupted parenchymal architecture, has emerged as the imaging modality of choice. However, in many cases, conventional MRI which provides useful structural findings are not enough for an accurate diagnosis.

Neuro-oncological imaging has evolved from a purely anatomy-based discipline to one that incorporates morphologic abnormality with physiologic alterations, cellular metabolism, and hemodynamics. Tremendous progress and widespread clinical use of physiology-based MR imaging have become an essential part of the diagnostic armamentarium to diagnose, guide surgery, monitor therapy response, and predict prognosis of patients with a brain tumour. The current most commonly used advanced techniques include diffusion-weighted imaging(DWI), MR Spectroscopy (MRS), Perfusion-weighted imaging (PWI)and Susceptibility weight imaging (SWI). These methods have played a pivotal role in the transition of clinical MR imaging from a purely morphology-based discipline to one that combines structure with function.

Integration of diagnostic information from above mentioned advanced MR imaging techniques can evaluate different tumour types, predict tumour grade, improve the classification accuracy, further differentiate tumour from non-neoplastic lesions, serially and noninvasively monitor tumour progression, and monitor the efficacy of therapy.

\section{Materials and Methods}

The present study was conducted in the Department of Radiology, Silchar Medical College and Hospital, Silchar for a period of one year from $1^{\text {st }}$ of June 2019 to $31^{\text {st }}$ of May 2020. Patients referred for radiological evaluation with clinically suspected intracranial mass of Silchar 
Medical College and Hospital of all age groups and genders were included. Patients with traumatic brain injury or had general contraindication for MRI and gadolinium-based contrast media were excluded. All of the patients underwent MR imaging study on a SIEMENS AVANTO FIT 1.5T SCANNER using a standard head coil with 240 x 240-mm FOV. Localizing sagittal T1W were obtained, then axial and sagittal T1W, axial and coronal T2-weighted, and axial FLAIR images of the brain were obtained.SWI and DW MR imaging was acquired in the axial plane. For PWI, a series of T2*weighted gradient-EPI was then acquired during the first pass of a bolus of contrast agent. Finally, contrast-enhanced axial T1-WI were obtained. MRS obtained with Multivoxel technique at intermediate $\mathrm{TE}=135 \mathrm{~ms}$.
In all cases, conventional and advanced MRI sequences were taken. Final diagnosis was done after correlation of imaging findings with clinical diagnosis, histopathological diagnosis, biochemical analysis and follow up scans when the patient was on conservative treatment.

\section{Results}

Our study included 60 patients of both sexes and 44(73.33\%) patients had neoplastic lesions and $16(26.67 \%)$ patients had non-neoplastic mass like lesions. Most common pathologies were metastases $(25.00 \%)$, high grade glioma $(16.67 \%)$, meningioma (15.00\%), low grade glioma $(8.33 \%)$, DNET (6.67\%), abscesses(10\%), tuberculoma $(8.33 \%)$, neurocysticercoses $(8.33 \%)$, and medulloblastoma $(1.67 \%)$.

Table 1: Distribution of cases according to the final diagnosis and distribution of lesions in different age groups and gender

\begin{tabular}{|c|c|c|c|c|}
\hline Pathology & No. of Cases & Percentage & $\begin{array}{c}\text { Age } \\
(\text { Mean } \pm \text { SD })\end{array}$ & M:F \\
\hline Neoplastic & 44 & $\mathbf{7 3 . 3 3 \%}$ & $50.27 \pm 15.82$ & $5: 4$ \\
\hline High Grade Glioma & 10 & $16.67 \%$ & $54.90 \pm 16.35$ & $3: 2$ \\
\hline Glioblastoma Multiforme & 6 & $10 \%$ & $62.50 \pm 5.89$ & $1: 1$ \\
\hline Grade III Astrocytoma & 3 & $5 \%$ & $54.00 \pm 4.58$ & 2:1 \\
\hline Diffuse Midline Glioma & 1 & $1.67 \%$ & 12 & \\
\hline Low Grade Glioma & 5 & $8.33 \%$ & $43.00 \pm 2.94$ & $3: 2$ \\
\hline Grade II Astrocytoma & 4 & $6.67 \%$ & $43.00 \pm 2.94$ & $3: 1$ \\
\hline Grade II Oligodendroglioma & 1 & $1.67 \%$ & 35 & \\
\hline Meningioma & 9 & $15.00 \%$ & $51.33 \pm 8.31$ & $1: 2$ \\
\hline Atypical Meningioma & 2 & $3.33 \%$ & $48.50 \pm 9.19$ & $1: 1$ \\
\hline Benign Meningioma & 7 & $11.67 \%$ & $52.14 \pm 8.63$ & $5: 2$ \\
\hline DNET & 4 & $6.67 \%$ & $20.00 \pm 2.58$ & 3:1 \\
\hline Medulloblastoma & 1 & $1.67 \%$ & 18 & - \\
\hline Metastasis & 15 & $25 \%$ & $59.94 \pm 8.46$ & $3: 2$ \\
\hline Non-Neoplastic & 16 & $26.67 \%$ & $\mathbf{4 2 . 2 5} \pm 12.86$ & 1.3:1 \\
\hline Abscess & 6 & $10 \%$ & $48.00 \pm 5.62$ & $2: 1$ \\
\hline Tuberculoma & 5 & $8.33 \%$ & $35.20 \pm 16.04$ & $3: 2$ \\
\hline Neurocysticercosis & 5 & $8.33 \%$ & $42.40 \pm 14.54$ & $3: 2$ \\
\hline Total & 60 & $100 \%$ & 48.13 \pm 15.40 & 1.3:1 \\
\hline
\end{tabular}




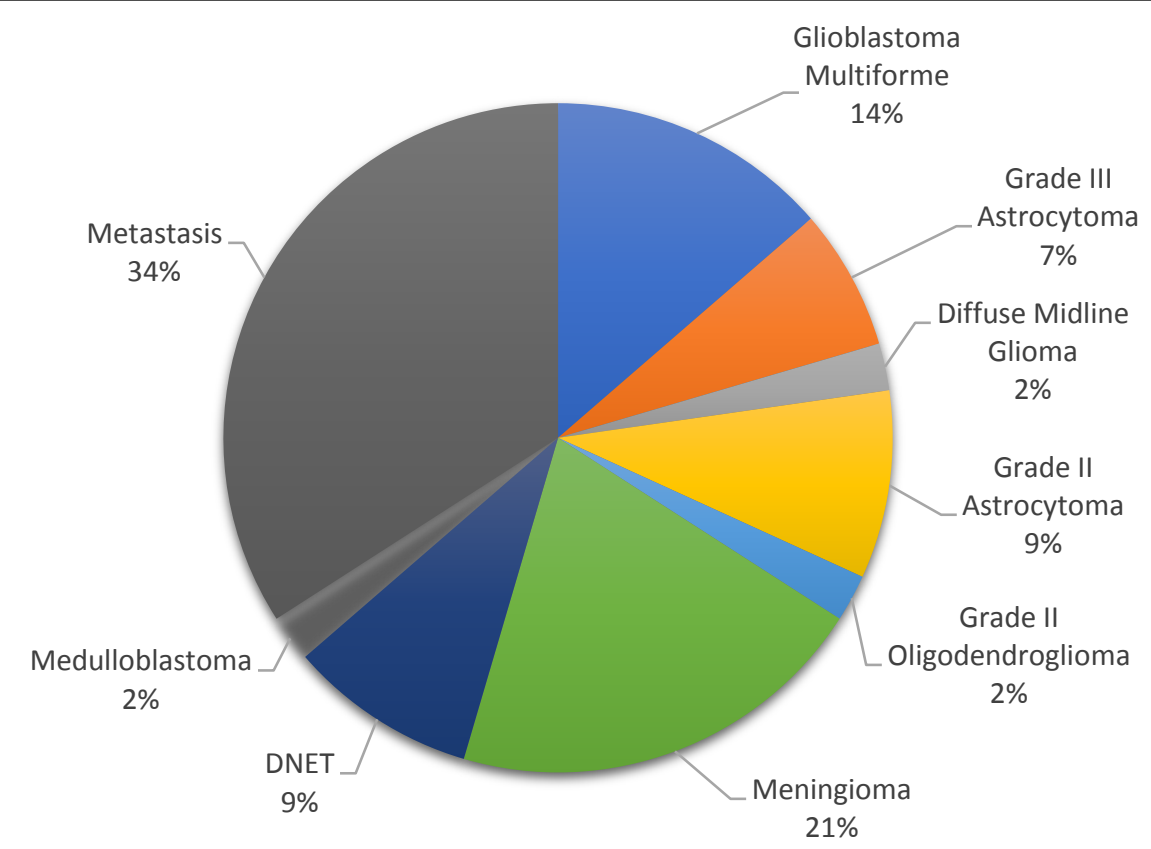

Chart 1: Showing distribution of neoplastic lesions

Most pathologies were common in older age groups (40-60yrs) except DNET, medulloblastoma, and diffuse midline glioma were present in the younger age group. Almost all pathologies were common in males except meningioma which was twice more common in female than male.

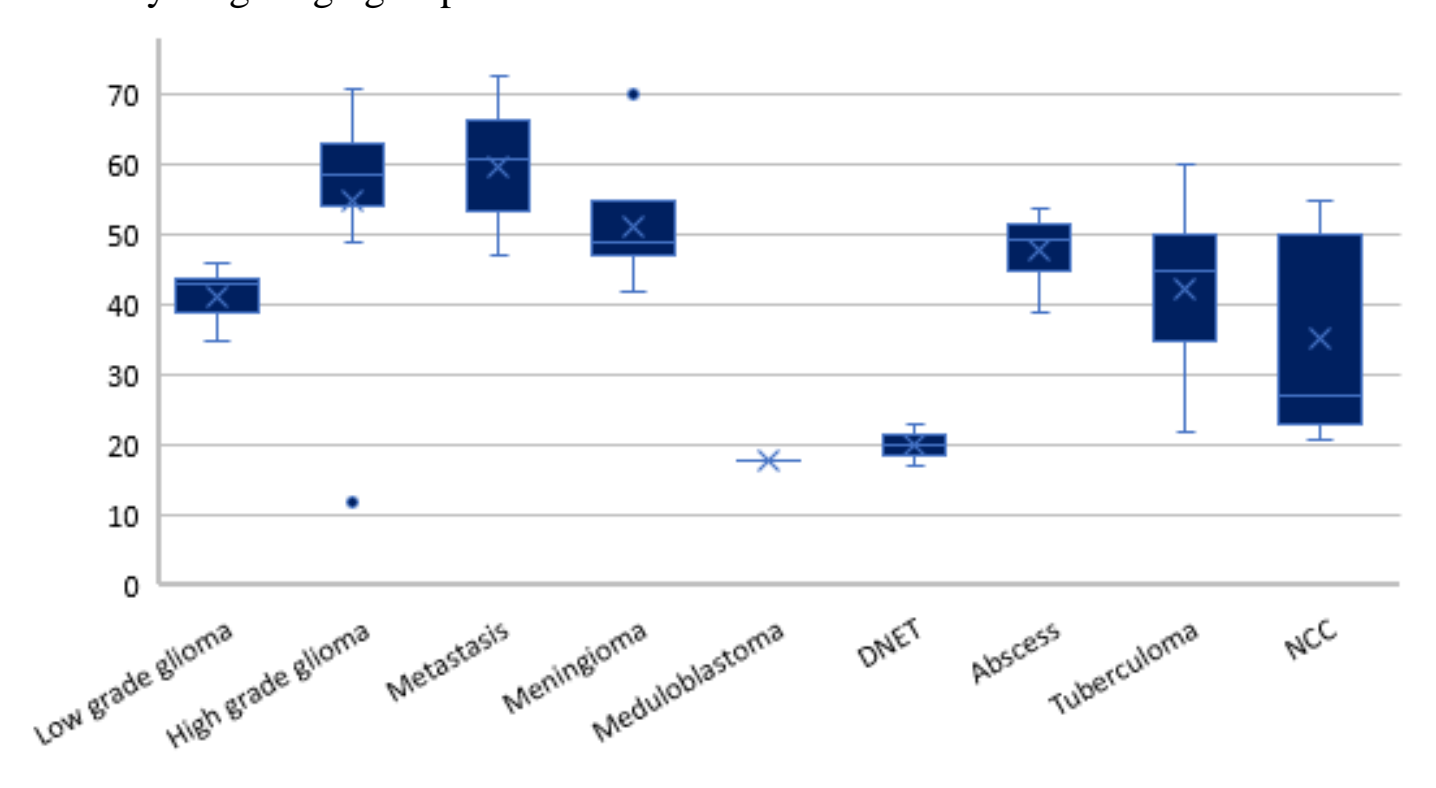

Chart 2: Showing distribution of lesions in different age groups 
Table 2: Conventional MR features in different pathologies

\begin{tabular}{|c|c|c|c|c|c|c|}
\hline \multirow{2}{*}{ Pathology } & \multirow{2}{*}{ Calcification } & \multirow{2}{*}{ Haemorrhage } & \multicolumn{2}{|c|}{ Margins } & \multicolumn{2}{|c|}{$\begin{array}{c}\text { Cystic/Necrotic } \\
\text { Changes }\end{array}$} \\
\hline & & & $\begin{array}{c}\text { Well } \\
\text { Defined }\end{array}$ & Ill Defined & Present & Absent \\
\hline Neoplastic & $8(18 \%)$ & $16(37 \%)$ & $24(54 \%)$ & $20(46 \%)$ & $24(55 \%)$ & $20(45 \%)$ \\
\hline High Grade Glioma & $1(10 \%)$ & $\mathbf{8}(\mathbf{8 0} \%)$ & $1(10 \%)$ & $9(90 \%)$ & $10(100 \%)$ & \\
\hline Glioblastoma Multiforme & $1(17 \%)$ & $6(100 \%)$ & & $6(100 \%)$ & $6(100 \%)$ & \\
\hline Grade III Astrocytoma & & $2(67 \%)$ & & $3(100 \%)$ & $3(100 \%)$ & \\
\hline Diffuse Midline Glioma & & & $1(100 \%)$ & & $1(100 \%)$ & \\
\hline Low Grade Glioma & $1(20 \%)$ & $1(20 \%)$ & $4(80 \%)$ & $1(20 \%)$ & & $5(100 \%)$ \\
\hline Grade II Astrocytoma & & & $4(100 \%)$ & & & $4(100 \%)$ \\
\hline Grade II Oligodendroglioma & $1(100 \%)$ & $1(100 \%)$ & & $1(100 \%)$ & & $1(100 \%)$ \\
\hline Meningioma & $6(67 \%)$ & $3(\mathbf{3 3} \%)$ & $6(67 \%)$ & $3(\mathbf{3 3 \%})$ & $4(44 \%)$ & $5(56 \%)$ \\
\hline Atypical Meningioma & $2(100 \%)$ & $2(100 \%)$ & & $2(100 \%)$ & $2(100 \%)$ & \\
\hline Benign Meningioma & $4(57 \%)$ & $1(14 \%)$ & $6(85 \%)$ & $1(14 \%)$ & $2(29 \%)$ & $5(71 \%)$ \\
\hline DNET & & & $4(100 \%)$ & & & $4(100 \%)$ \\
\hline Medulloblastoma & & & $1(100 \%)$ & & $1(100 \%)$ & \\
\hline Metastasis & & $4(27 \%)$ & $4(27 \%)$ & $11(73 \%)$ & $9(60 \%)$ & $6(40 \%)$ \\
\hline Non-Neoplastic & $3(19 \%)$ & $1(6 \%)$ & $16(100 \%)$ & & $16(100 \%)$ & \\
\hline Abscess & & & $6(100 \%)$ & & $6(100 \%)$ & \\
\hline Neurocysticercosis & $3(60 \%)$ & & $5(100 \%)$ & & $5(100 \%)$ & \\
\hline Tuberculoma & & $1(20 \%)$ & $5(100 \%)$ & & $5(100 \%)$ & \\
\hline Total & $11(18 \%)$ & $17(28 \%)$ & $36(60 \%)$ & $24(40 \%)$ & $40(67 \%)$ & $20(33 \%)$ \\
\hline
\end{tabular}

Calcification in neoplastic group was common in $6(67 \%)$ cases of meningioma, 1 case $(16.67 \%)$ of glioblastoma multiforme and 1 case(100\%)of grade II oligodendroglioma. No calcification was present in cases of grade II diffuse astrocytoma. In non-neoplastic pathologies calcification was seen in $60 \%$ cases of neurocysticercosis.Haemorrhage, marked perilesional oedema, ill-defined margins, cystic/necrotic changes were more common in HGG than the LGG. Haemorrhage was present in all cases of glioblastoma multiforme, 2 case (67\%)of grade III anaplastic astrocytoma and 1 case $(100 \%)$ of grade II oligodendroglioma. No haemorrhage was present in any case of grade II diffuse astrocytoma. Cyst/necrotic changes were present in all cases of HGG. None of LGG showed cystic or necrotic changes in any of cases. In non-neoplastic pathologies all lesions had well defined margins and $1(20 \%)$ of cases tuberculoma had hemorrhagic foci.

Table 3: Distribution of nADC value in lesion and perilesional oedema in DWI and rCBV in PWI among different pathology

\begin{tabular}{|c|c|c|c|}
\hline Pathology & $\begin{array}{c}\mathrm{nADC}_{\mathrm{L}} \\
(\mathrm{Mean} \pm \mathrm{SD})\end{array}$ & $\begin{array}{c}\text { nADC } \text { PLE } \\
(\text { Mean } \pm \text { SD })\end{array}$ & $\begin{array}{c}\text { rCBV } \\
(\mathrm{Mean} \pm \mathrm{SD})\end{array}$ \\
\hline Neoplastic & $1.27 \pm 0.43$ & $1.74 \pm 0.17$ & $5.12 \pm 3.19$ \\
\hline High Grade Glioma & $\mathbf{1 . 0 7} \pm \mathbf{0 . 0 8}$ & $1.49 \pm 0.12$ & $4.54 \pm 1.41$ \\
\hline Glioblastoma Multiforme & $1.08 \pm 0.09$ & $1.44 \pm 0.11$ & $5.36 \pm 0.68$ \\
\hline Grade III Astrocytoma & $1.04 \pm 0.07$ & $1.60 \pm 0.04$ & $4.00 \pm 0.30$ \\
\hline Diffuse Midline Glioma & 1.12 & 1.46 & 1.29 \\
\hline Low Grade Glioma & $1.41 \pm 0.06$ & $1.87 \pm 0.09$ & $1.33 \pm 0.27$ \\
\hline
\end{tabular}




\begin{tabular}{|c|c|c|c|}
\hline Grade II Astrocytoma & $1.42 \pm 0.06$ & $1.88 \pm 0.10$ & $1.37 \pm 0.30$ \\
\hline Grade II Oligodendroglioma & 1.36 & 1.82 & 1.21 \\
\hline Meningioma & $\mathbf{1 . 0 8} \pm \mathbf{0 . 1 2}$ & $\mathbf{1 . 8 0} \pm \mathbf{0 . 0 9}$ & $\mathbf{1 0 . 0 7} \pm \mathbf{1 . 2 2}$ \\
\hline Atypical Meningioma & $0.91 \pm 0.10$ & $1.84 \pm 0.12$ & $11.80 \pm 1.34$ \\
\hline Benign Meningioma & $1.12 \pm 0.08$ & $1.79 \pm 0.09$ & $9.58 \pm 0.64$ \\
\hline DNET & $\mathbf{2 . 5 4 3} \pm \mathbf{0 . 1 2}$ & $\mathbf{1 . 8 1} \pm \mathbf{0 . 0 9}$ & $\mathbf{0 . 7 9} \pm \mathbf{0 . 0 4}$ \\
\hline Medulloblastoma & $\mathbf{0 . 9 9}$ & $\mathbf{1 . 4 6}$ & $\mathbf{1 . 3 7}$ \\
\hline Metastasis & $\mathbf{1 . 1 6} \pm \mathbf{0 . 1 1}$ & $\mathbf{1 . 8 2} \pm \mathbf{0 . 0 8}$ & $\mathbf{5 . 1 9} \pm \mathbf{1 . 3 0}$ \\
\hline Non-Neoplastic & $\mathbf{0 . 7 1} \pm \mathbf{0 . 0 9}$ & $\mathbf{1 . 8 1} \pm \mathbf{0 . 1 0}$ & $\mathbf{1 . 6 9} \pm \mathbf{1 . 1 1}$ \\
\hline Abscess & $0.65 \pm 0.05$ & $\mathbf{1 . 8 5} \pm 0.10$ & $0.77 \pm 0.06$ \\
\hline NCC & $0.80 \pm 0.10$ & $1.76 \pm 0.09$ & $1.27 \pm 0.12$ \\
\hline Tuberculoma & $0.69 \pm 0.06$ & $1.81 \pm 0.09$ & $3.20 \pm 0.51$ \\
\hline
\end{tabular}

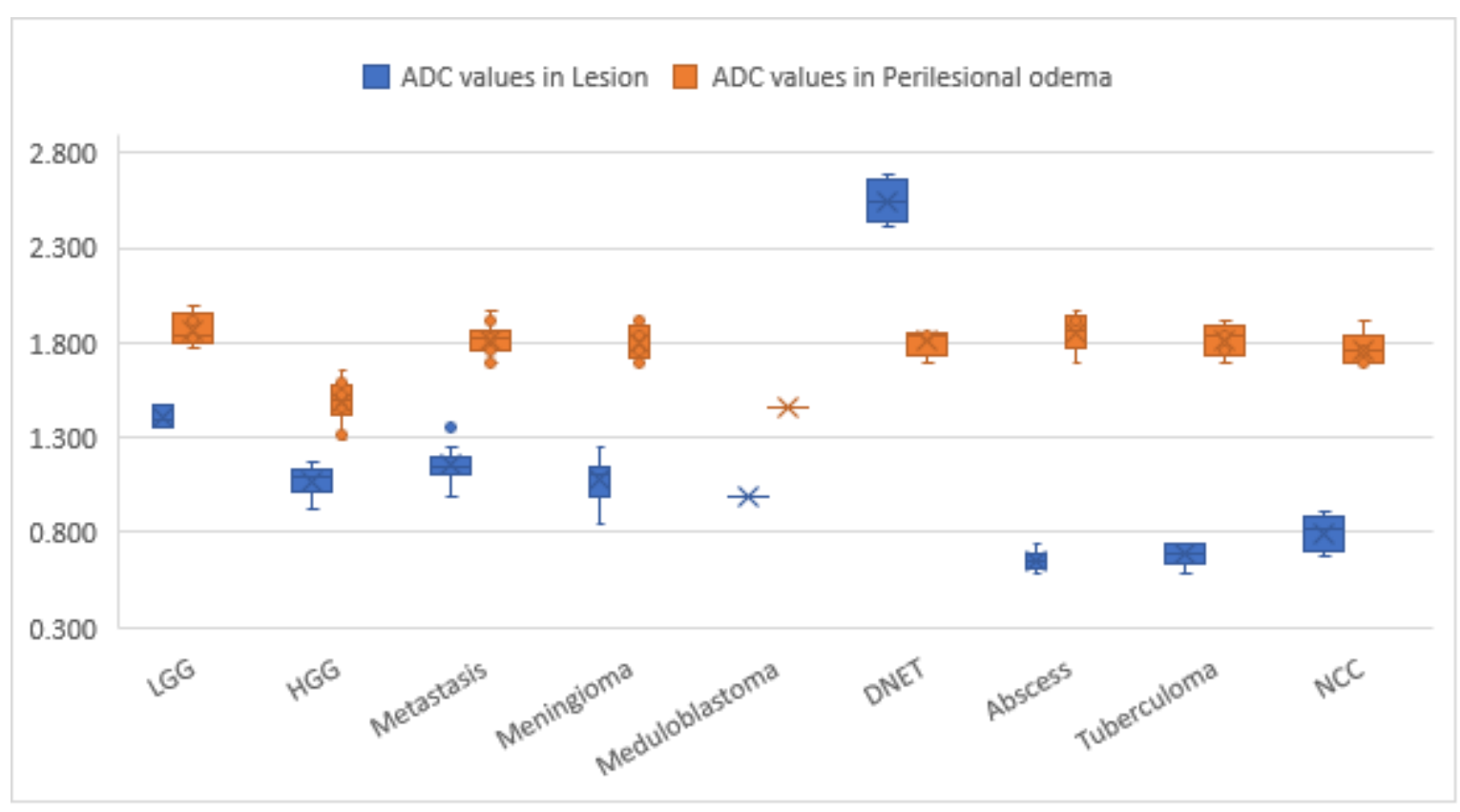

Chart 3: Distribution of $\mathrm{nADC}$ value in the lesion and perilesional oedema among different pathology

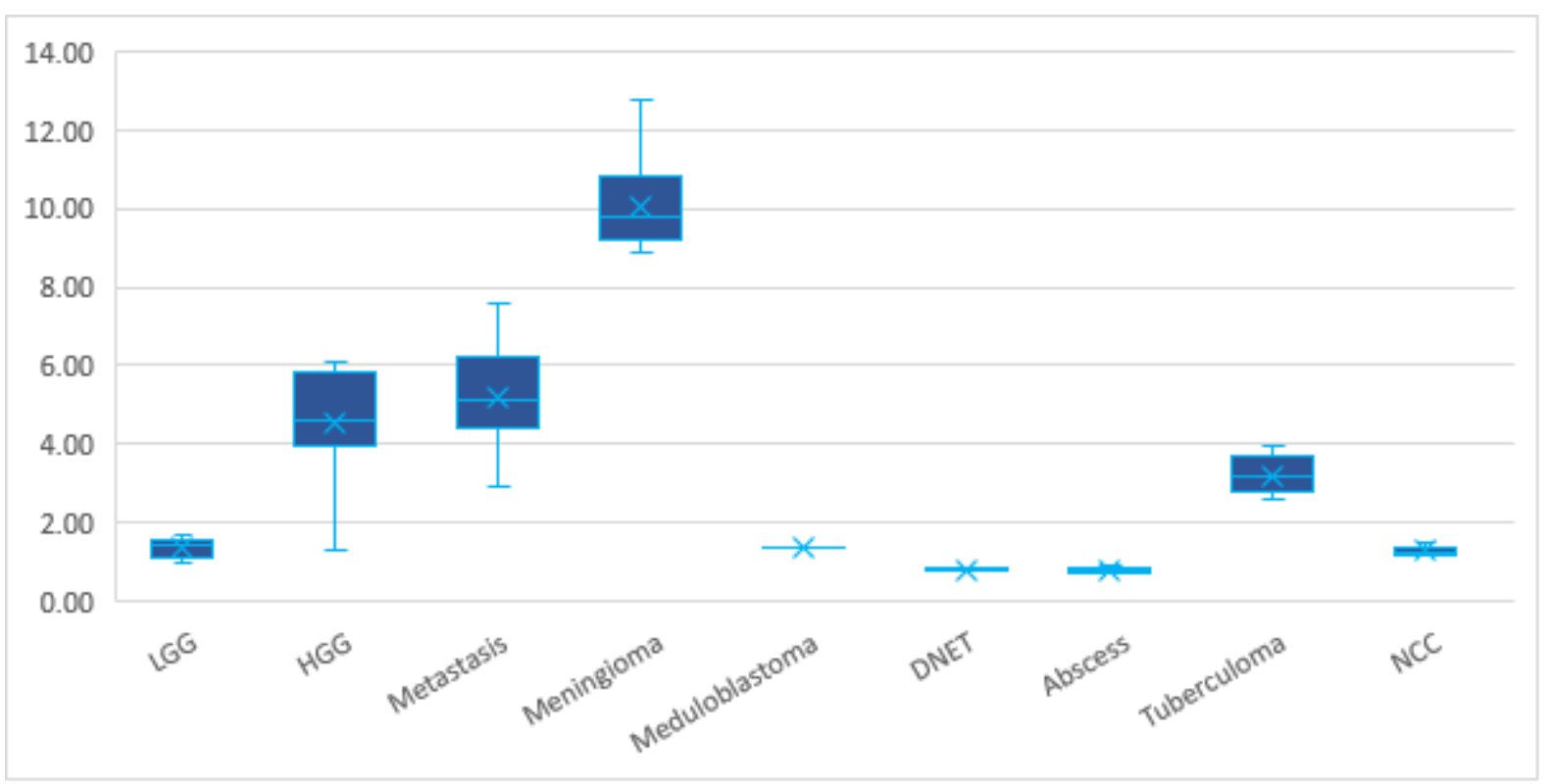

Chart 4: Showing rCBV values in different pathologies 
In neoplastic pathologies LGG, ADC values were higher than the HGG, suggesting no restriction of diffusion and $\mathrm{ADC}$ values in perilesional oedema were not significantly lower. ADC values were lower in HGG and metastatic lesions. However, the ADC values in perilesional oedema were lower in HGG than the metastatic lesions, suggesting infiltrative process in HGG. One case of oligodendroglioma and medulloblastoma shows decreased ADC values. DNET shows significantly higher ADC values within the lesion, suggesting increased diffusivity. Atypical meningioma shows lower ADC values than the benign meningioma and ADC values in perilesional oedema were not significantly lower in both grades of meningiomas. Non-neoplastic pathologies show lower ADC values suggesting restricted diffusion.
Abscess and tuberculoma both show lower ADC values. However perilesional ADC values were not decreased.

On PWI, rCBV values were lower in LGG than the HGG and metastatic lesions. However, discrimination between metastases and HGG was not possible with rCBV values alone. Each of one case of oligodendroglioma and medulloblastoma showed lower rCBV values. Meningiomas showed highly increased rCBV values suggesting hyper vascular tumor. Atypical meningioma shows higher rCBV values than the benign meningioma. DNET show significantly lower rCBV values within the lesion, suggesting absent perfusion. Abscess showed significantly lower rCBV values in the wall, while walls of tuberculomas showed higher rCBV values.

Table 4: Distribution of MR spectroscopy spectrum values in different pathologies

\begin{tabular}{|c|c|c|c|c|}
\hline Pathology & $\begin{array}{c}\text { NAA/Cr } \\
(\text { MeantSD) }\end{array}$ & $\begin{array}{c}\text { Cho/NAA } \\
(\text { MeantSD) }\end{array}$ & $\begin{array}{c}\text { Cho/Cr } \\
(\text { Mean } \pm \text { SD) }\end{array}$ & Other \\
\hline Neoplastic & $1.22 \pm 0.69$ & $3.01 \pm 1.86$ & $2.86 \pm 1.41$ & \\
\hline High Grade Glioma & $0.33 \pm 0.11$ & $5.75 \pm 1.15$ & $2.25 \pm 0.36$ & \\
\hline GBM & $0.38 \pm 0.11$ & $5.34 \pm 1.03$ & $2.21 \pm 0.27$ & Lac, Lip \\
\hline Grade III Astrocytoma & $0.24 \pm 0.05$ & $6.91 \pm 0.59$ & $2.45 \pm 0.52$ & Lac \\
\hline Diffuse Midline Glioma & 0.34 & 4.79 & 1.94 & Lac \\
\hline Low Grade Glioma & $0.56 \pm 0.08$ & $3.43 \pm 0.55$ & $1.60 \pm 0.16$ & \\
\hline Grade II Astrocytoma & $0.58 \pm 0.09$ & $3.33 \pm 0.59$ & $1.54 \pm 0.12$ & \\
\hline Grade II Oligodendroglioma & 0.51 & 3.82 & 1.83 & \\
\hline Meningioma & $1.47 \pm 0.32$ & $2.55 \pm 1.4$ & $3.41 \pm 1.29$ & Ala \\
\hline Atypical Meningioma & $1.12 \pm 0.16$ & $4.63 \pm 0.60$ & $5.16 \pm 1.23$ & Ala,Lac \\
\hline Benign Meningioma & $1.58 \pm 0.27$ & $1.96 \pm 0.85$ & $2.91 \pm 0.81$ & Ala \\
\hline DNET & $1.49 \pm 0.19$ & $0.78 \pm 0.05$ & $1.16 \pm 0.22$ & \\
\hline Medulloblastoma & 0.97 & 8.12 & 7.56 & \\
\hline Metastasis & $1.83 \pm 0.46$ & $1.99 \pm 0.65$ & $3.50 \pm 1.10$ & Lac,Lipid \\
\hline Non-Neoplastic & $0.97 \pm 0.47$ & $2.43 \pm 1.10$ & $1.97 \pm 0.83$ & \\
\hline Abscess & $1.47 \pm 0.40$ & $2.53 \pm 1.00$ & $2.73 \pm 0.43$ & Lac,AA,Suc \\
\hline $\mathrm{NCC}$ & $0.74 \pm 0.06$ & $1.23 \pm 0.06$ & $0.90 \pm 0.05$ & Lac,AA,Suc, Ala \\
\hline Tuberculoma & $0.59 \pm 0.05$ & $3.50 \pm 0.09$ & $2.14 \pm 0.12$ & Lac,AA,SucLipid \\
\hline
\end{tabular}




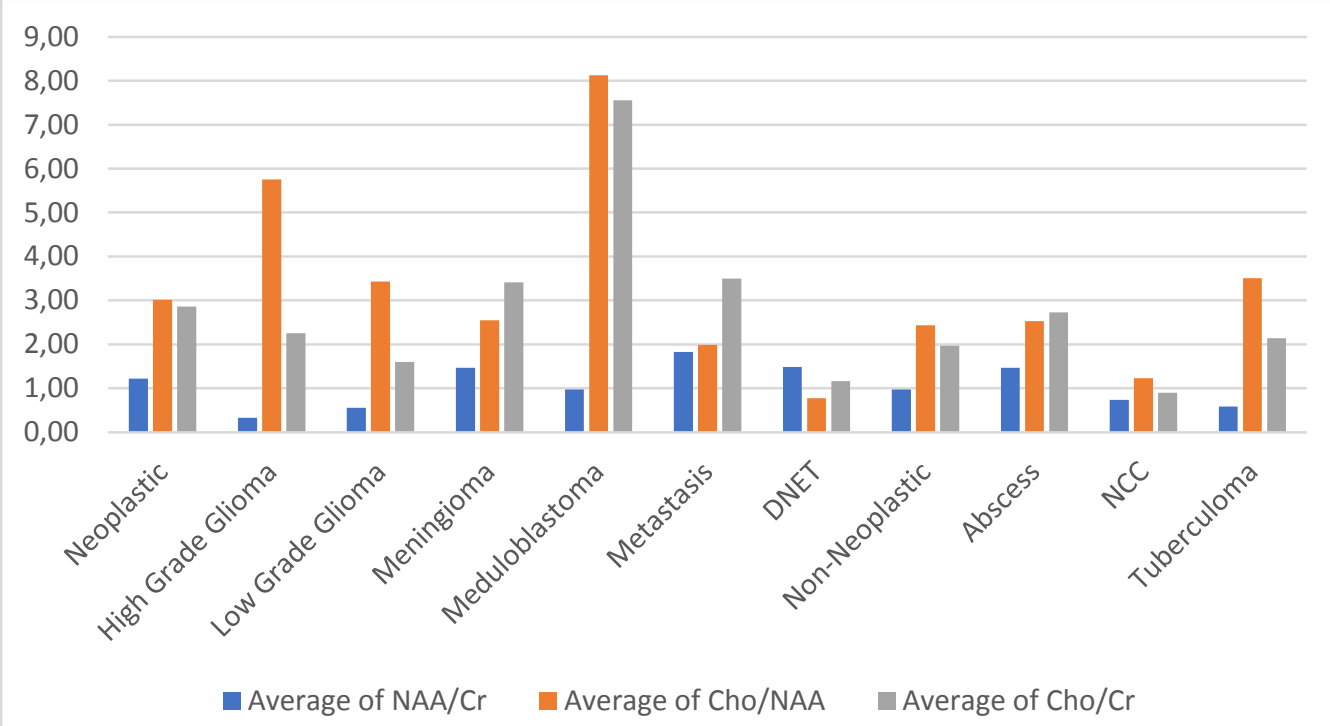

Chart 5: showing distribution of MRS values in different pathologies

On spectroscopy, non-neoplastic lesions such as brain abscesses are marked by decreases in Cho, Crand NAA, while tumors generally have elevated Cho and decreased levels of $\mathrm{Cr}$ and NAA.In HGG, choline peaks and Lactate peaks were higher than the LGG.A few tumors, including glioblastoma multiforme and metastases, showed lipid signal combined with lactate signal. Meningioma showed prominent choline, decreased NAA, Creatine, and presence of alanine. Higher grade meningiomas showed lactate peak.One case of medulloblastoma showed highly increased choline. DNETs showed nearly normal MRS spectrum. In abscesses, there were various combinations of lactate, acetate, succinate, amino acids. In cysticercosis, resonances of lactate, succinate, alanine, acetate were present. Tuberculomas had a high peak of lipids, more choline, and less NAA and creatine. The choline/creatine ratio was higher than 1 in all tuberculomas compared to none of the cysticerci.

\section{Case 1: Glioblastoma Multiforme}

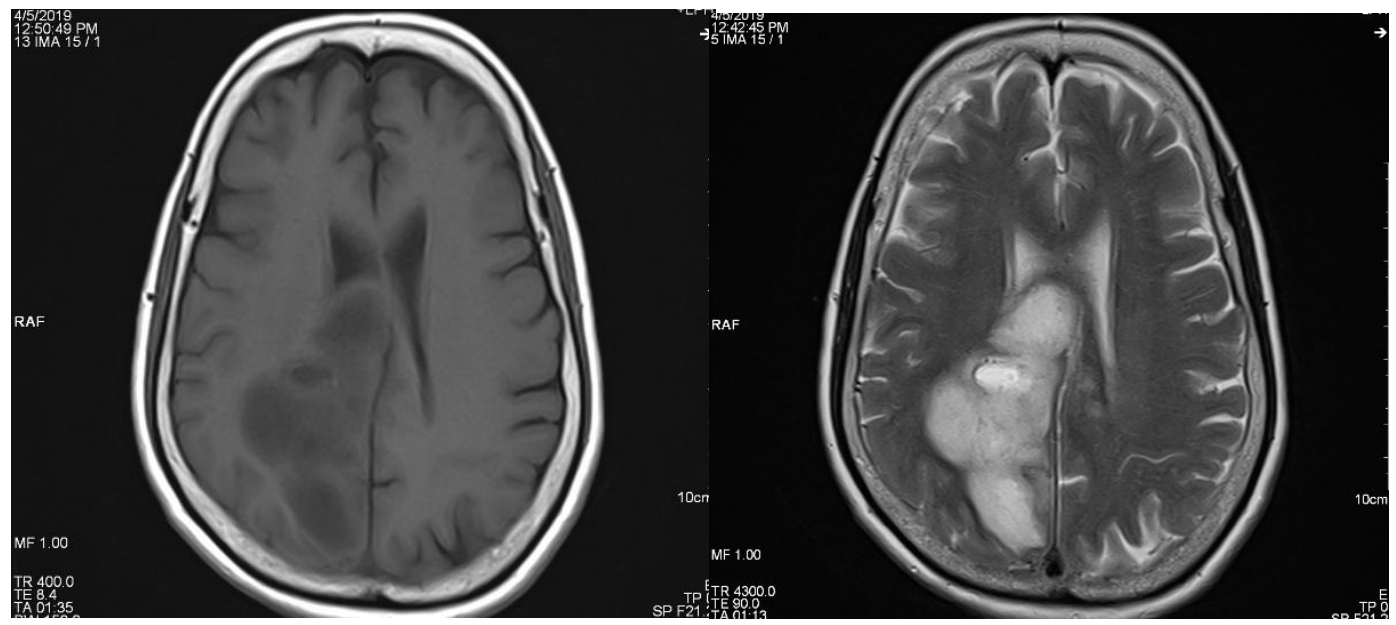

(A)Axial T1WI

(B)Axial T2WI

A case of glioblastoma multiforme in a 65-year-old-female. (A) hypointense lesion on T1WI and (B)Hyperintense on T2WI in the right parietooccipital region. 


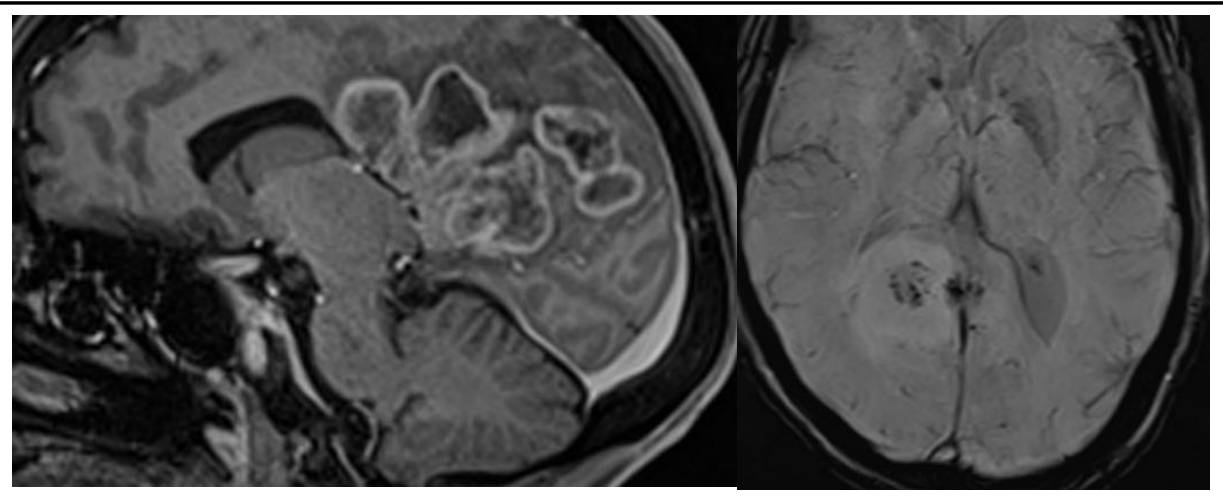

(C) Sagittal T1+C

(D) SWI

Sagittal $\mathrm{T} 1+\mathrm{C}(\mathrm{C})$ images show multiple rings enhancing lesions. SWI (D) show blooming due to haemorrhagic foci.

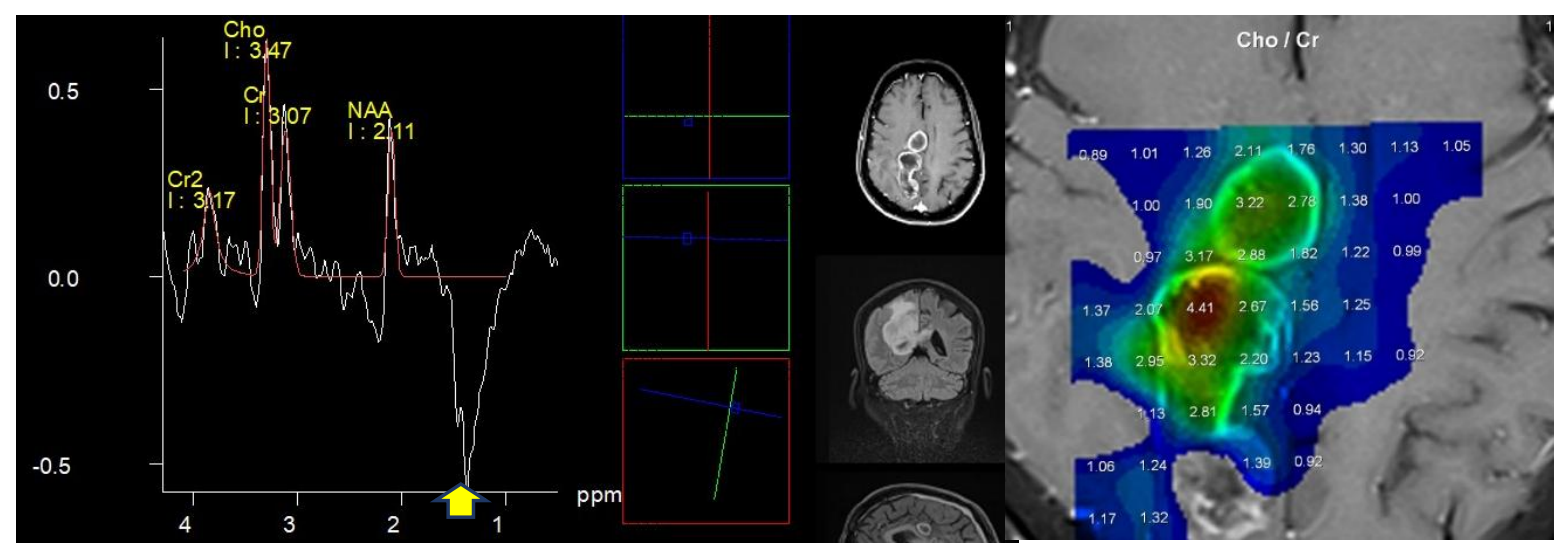

(E)MRS

(F)Cho/Cr ratio map

On MRS (E) demonstrates elevated Cho and decreased NAA, as well as increased lactate (marked with yellow arrow), these findings are further illustrated with spectroscopic colour map(F) of the cho/cr ratios.

Case 2: Diffuse Midline Glioma

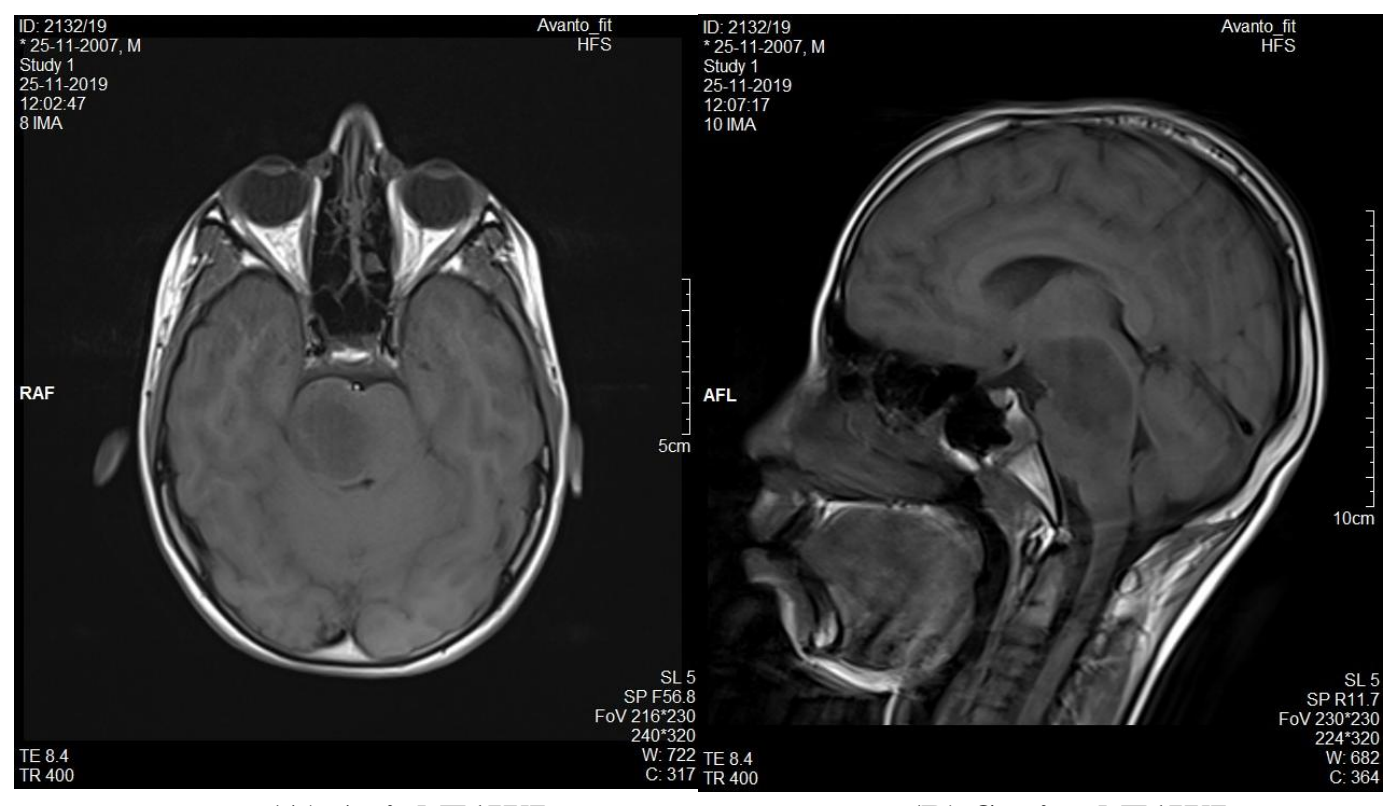

(A) Axial T1WI

(B) Sagittal T1WI 


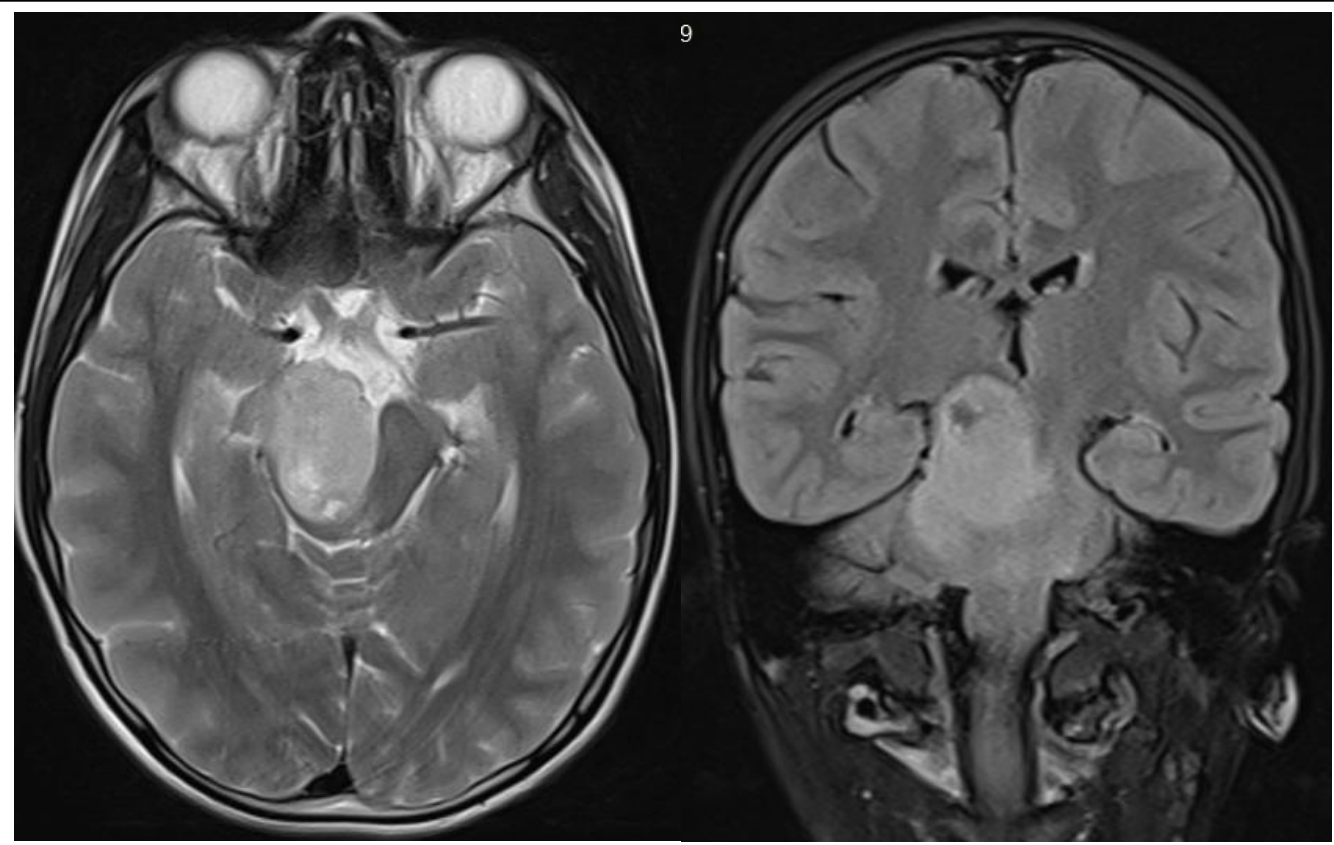

(C)Axial T2WI

(D)Coronal FLAIR

A case of diffuse midline glioma in a 12-year-old-child. (A)Axial and (B) Sagittal T1WI shows hypointense and (C) Axial T2WI and(D)Coronal FLAIR images show hyperintense lesion involving pons and midbrain with mass effect.

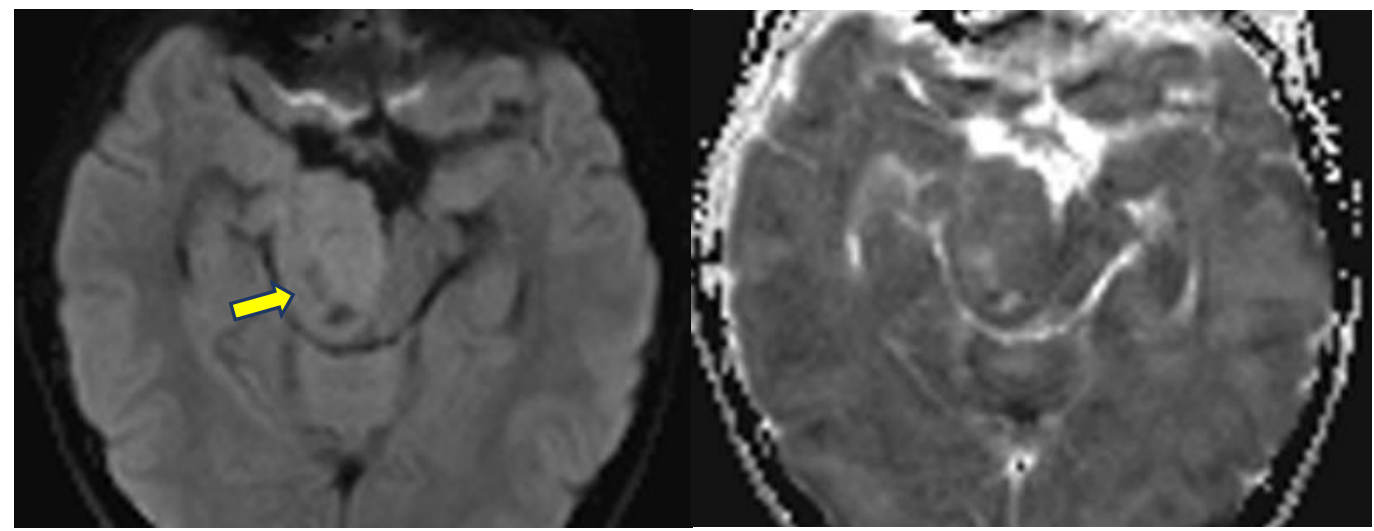

(G)DWI

(H)ADC

(G)DWI and (H)ADC images show mild diffusion restriction, however foci of increased diffusion are present(necrotic area, marked with yellow arrow)

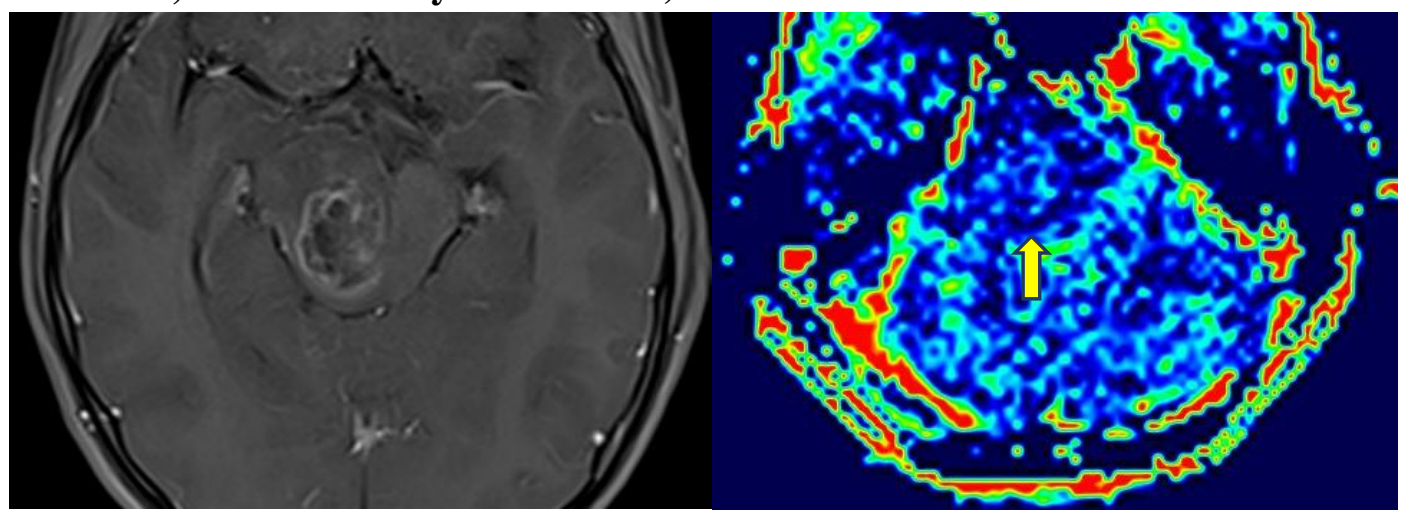

(I)Axial T1+C

(J)PWI

(I)T1+C show enhancement in peripheral part of lesion and (J)PWI show no significant perfusion on the corresponding parametric maps(marked with yellow arrow) 


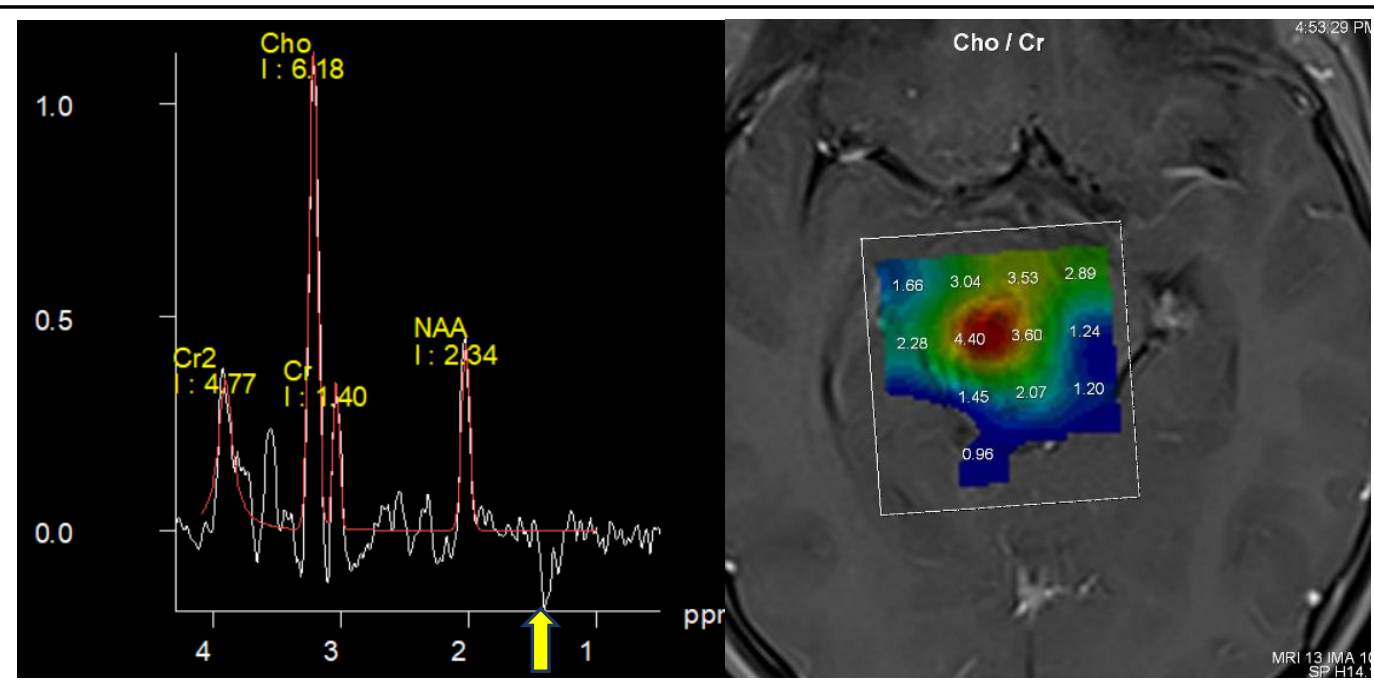

(K)MRS

(L)Cho/Cr ratio map

On MRS (K) demonstrates markedly elevated Cho and decreased NAA, as well as increased lactate(marked with yellow arrow), these findings are further illustrated with spectroscopic colour $\operatorname{map}(\mathrm{L})$ of the choline/creatine ratios.

\section{Case 3: Metastasis}

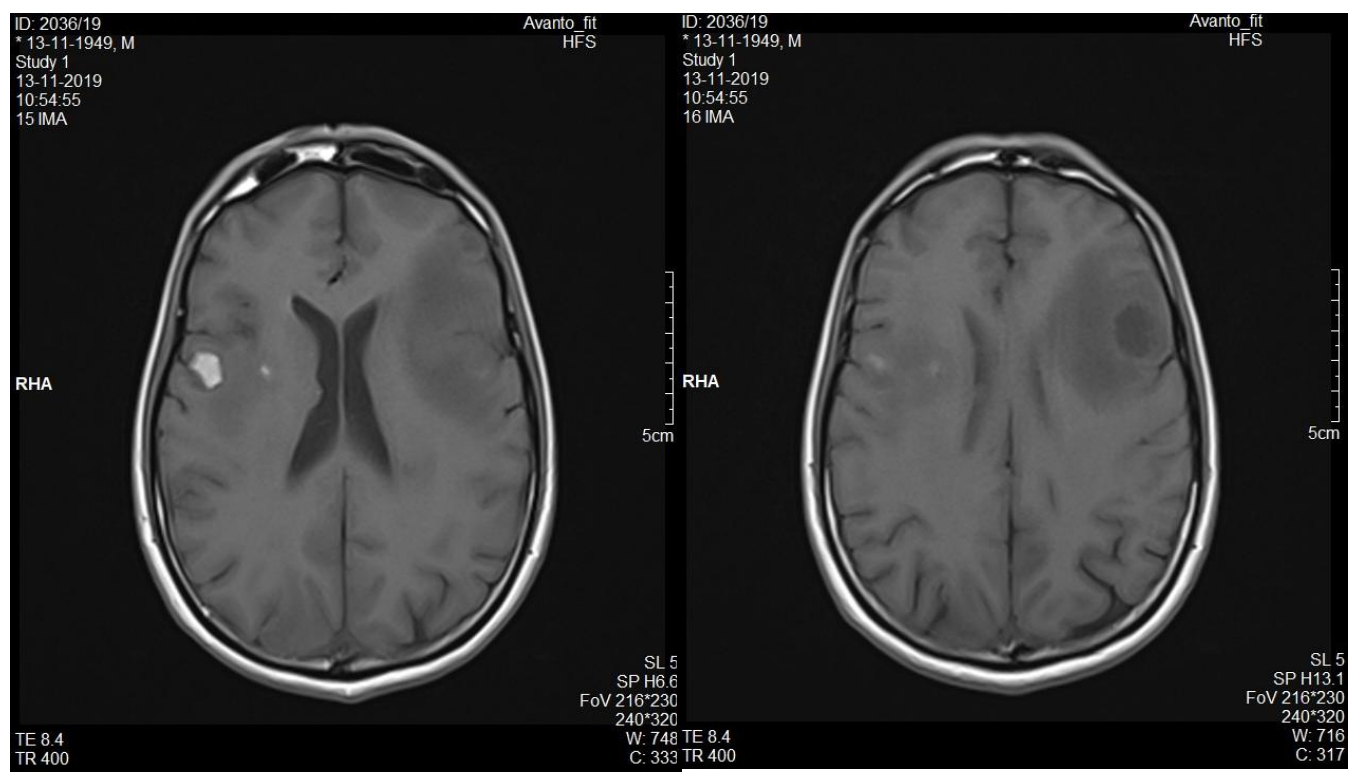

(A)Axial T1WI 


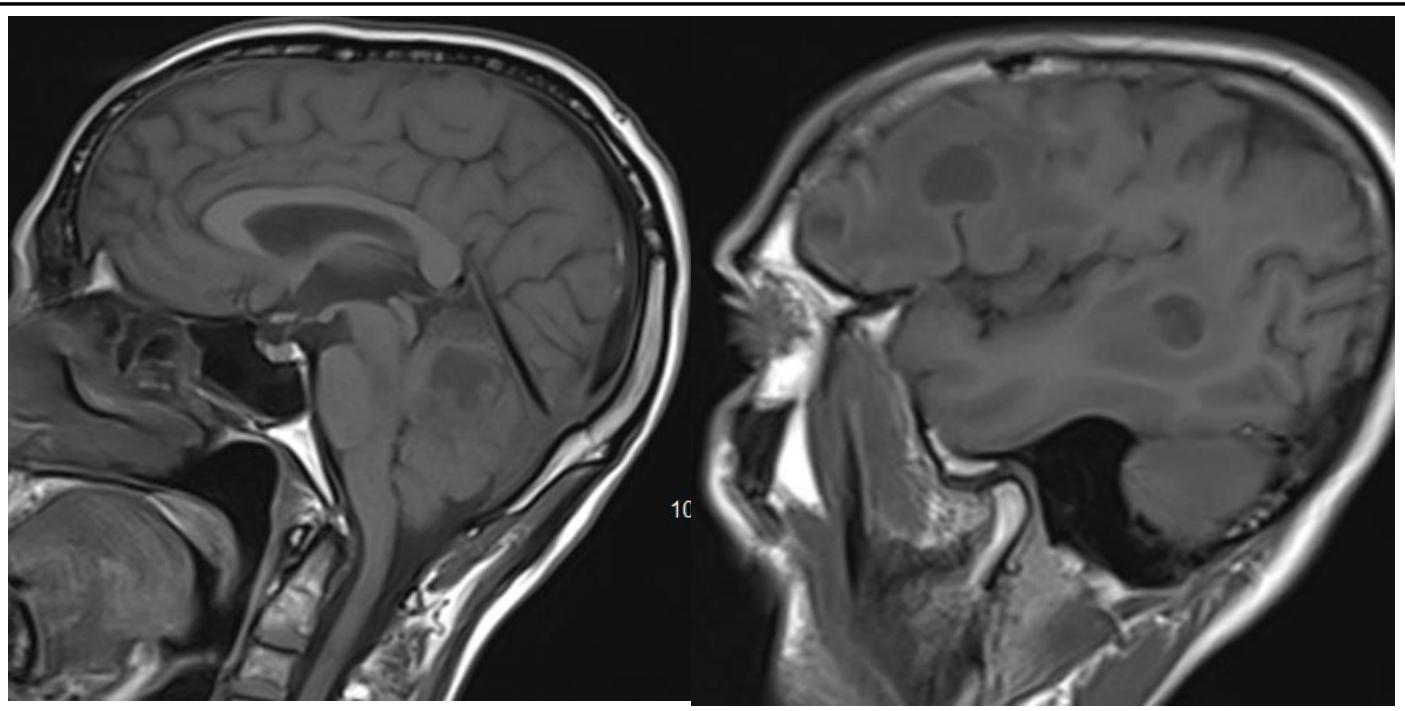

(B) Sagittal T1WI

A case of intracranial lung metastasis in a 70-year-old-man.(A)Axial and(B)sagittal T1WI at different levels shows multiple hypointense(two lesions were hyperintense due to haemorrhage)involving bilateral cerebral hemisphere, mid brain and cerebellum

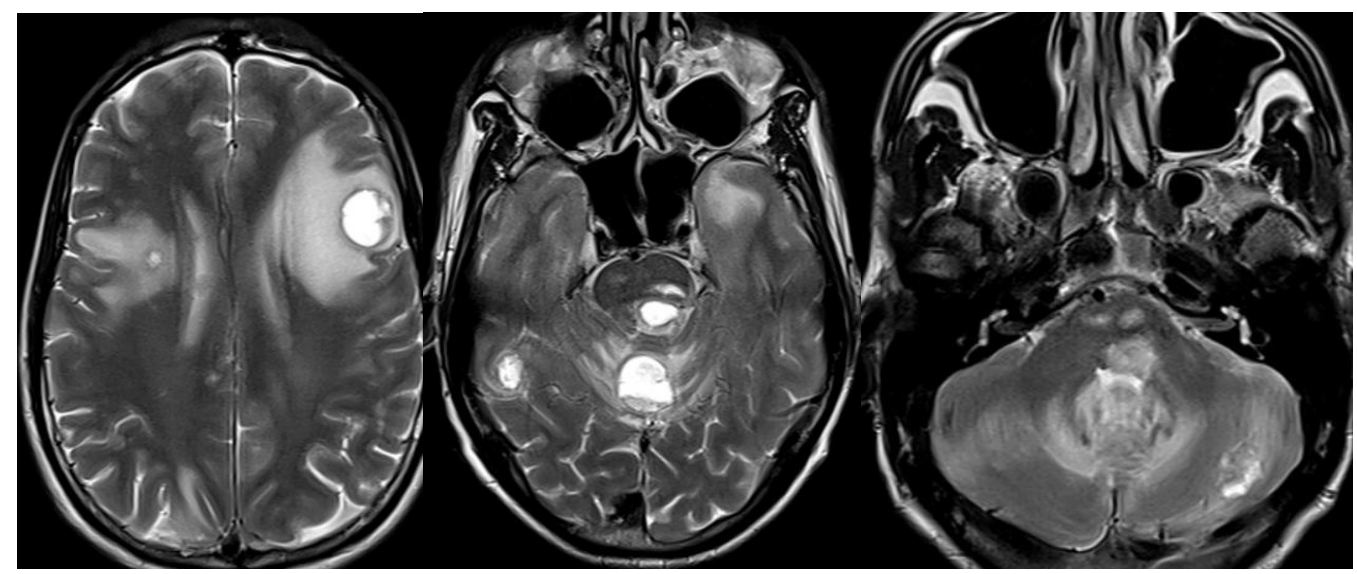

(C)Axial T2WI

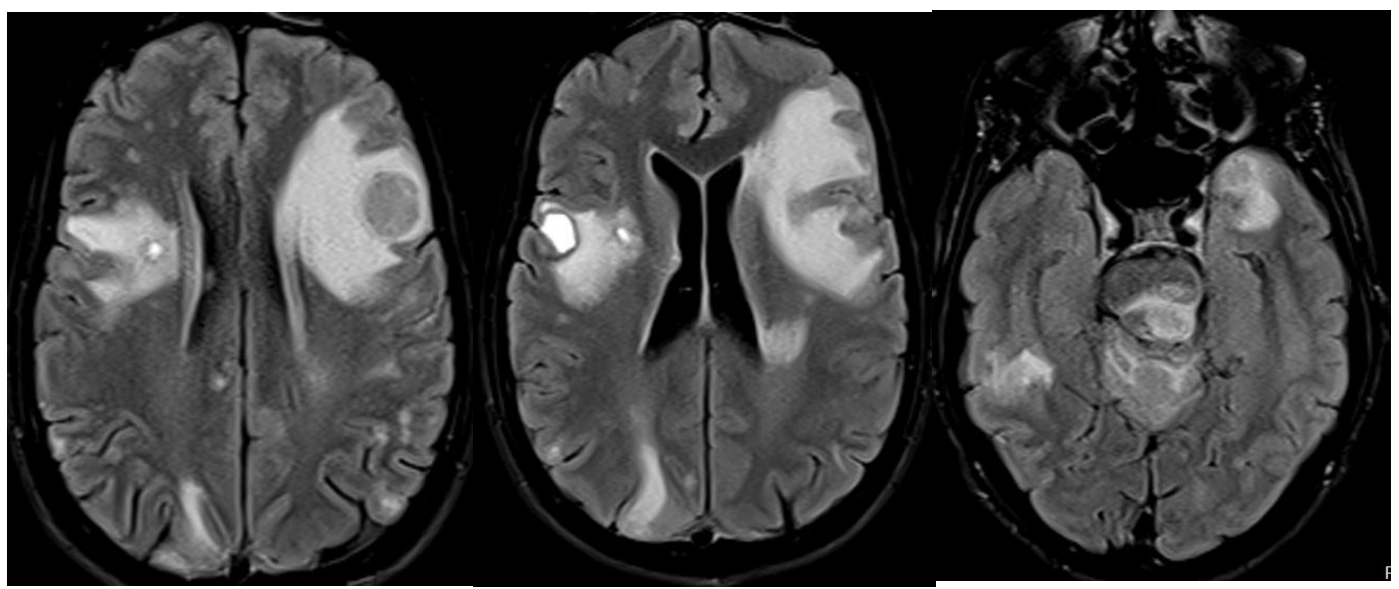

(D)Axial FLAIR

(C)Axial T2WI and(D)Axial FLAIR images at different section, shows hyperintense lesion on T2WI and hyper/isointense lesions with surrounding oedema. 


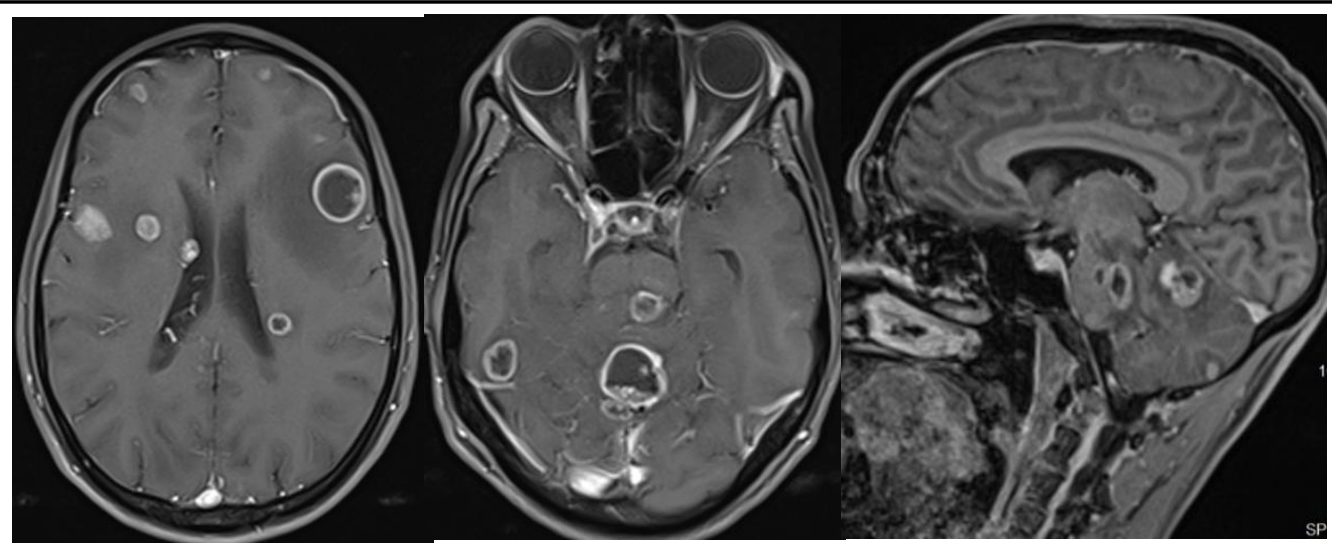

(E)Axial T1+C

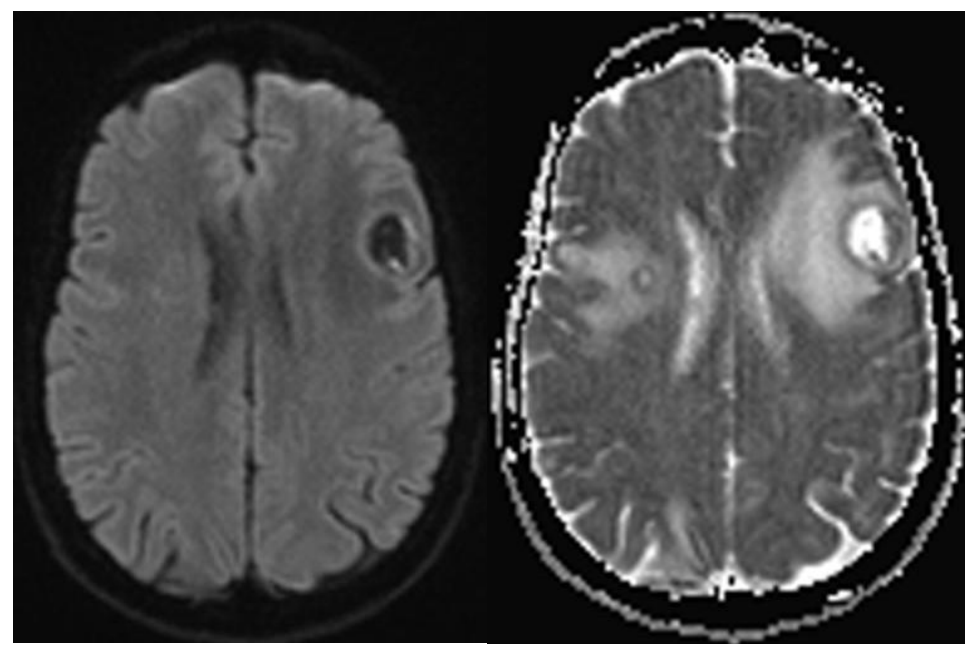

(F)DWI

(G)ADC

On $\mathrm{T} 1+\mathrm{C}(\mathrm{E})$ images lesions show rim enhancement. On(F)DWI and(G)ADC no restriction was present in centre of lesions(corresponding to necrosis), however mild restriction was present in wall of the lesion.

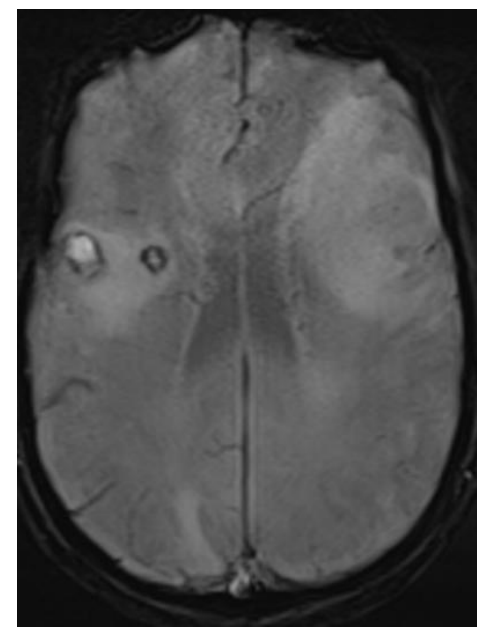

(H)SWI

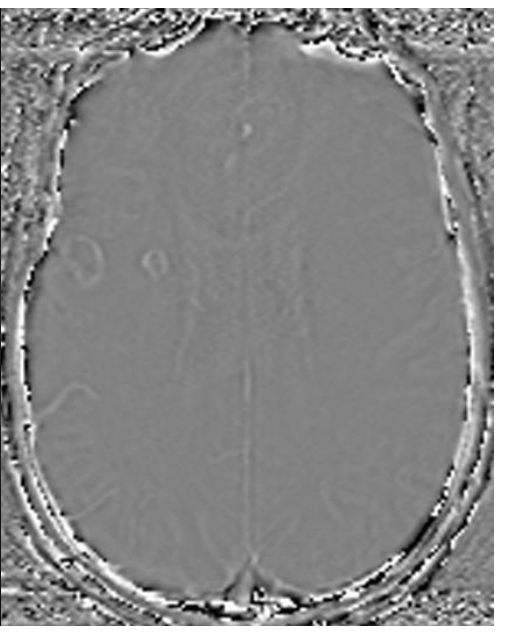

(I)Phase images

SWI(H)and phase images(I)show blooming in one lesion due to haemorrhage. 


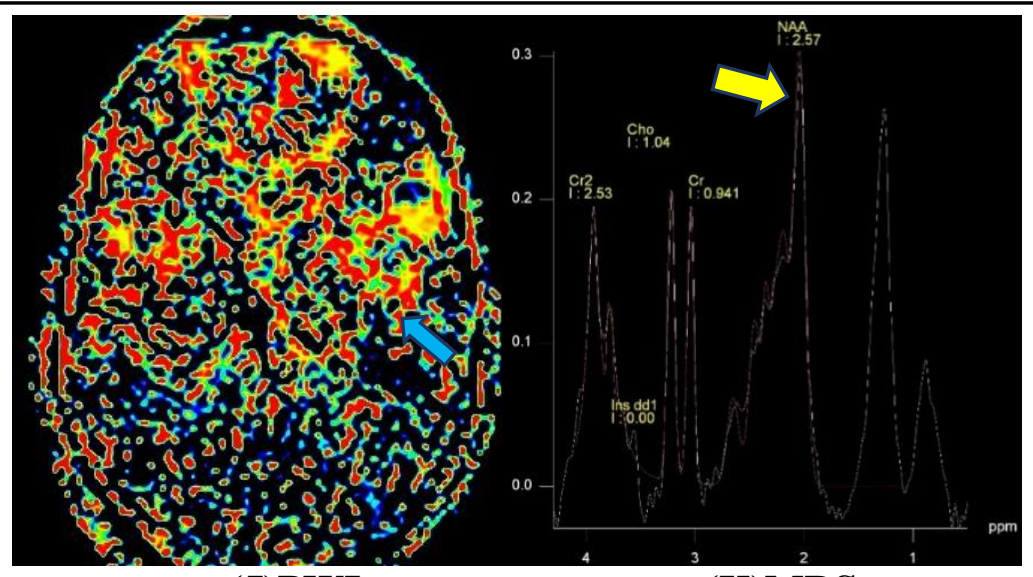

(J)PWI

(K)MRS

PWI(J) rCBV colour map shows markedly increased perfusion at the margin of the lesion(blue arrow); MR spectrum(K)of the lesion shows elevation of the lactate(Lac)and lipid peak(at 1.33 ppm)(yellow arrow)at short TE.

Case 4: Atypical Meningioma

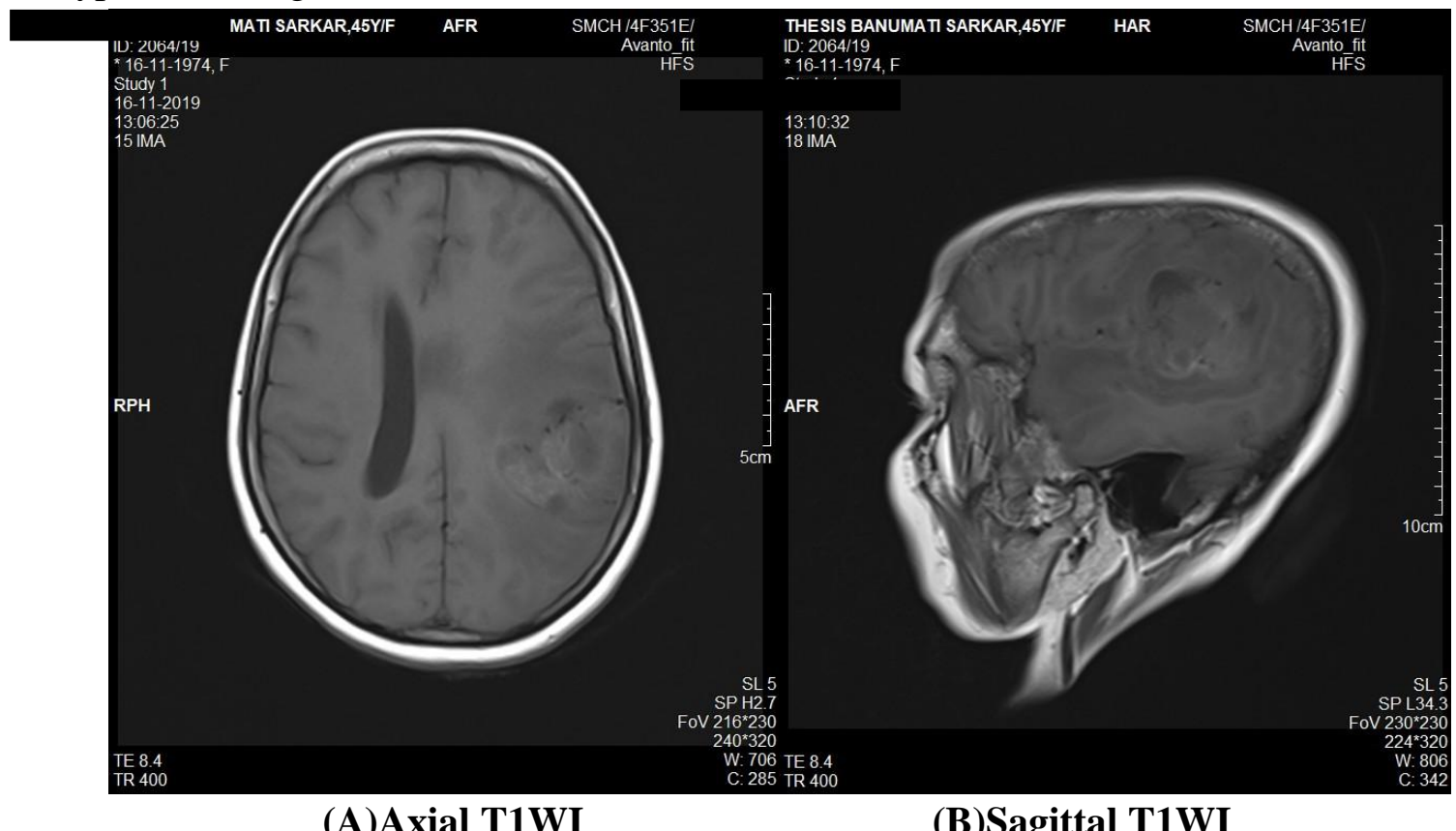

(A)Axial T1WI

(B)Sagittal T1WI 


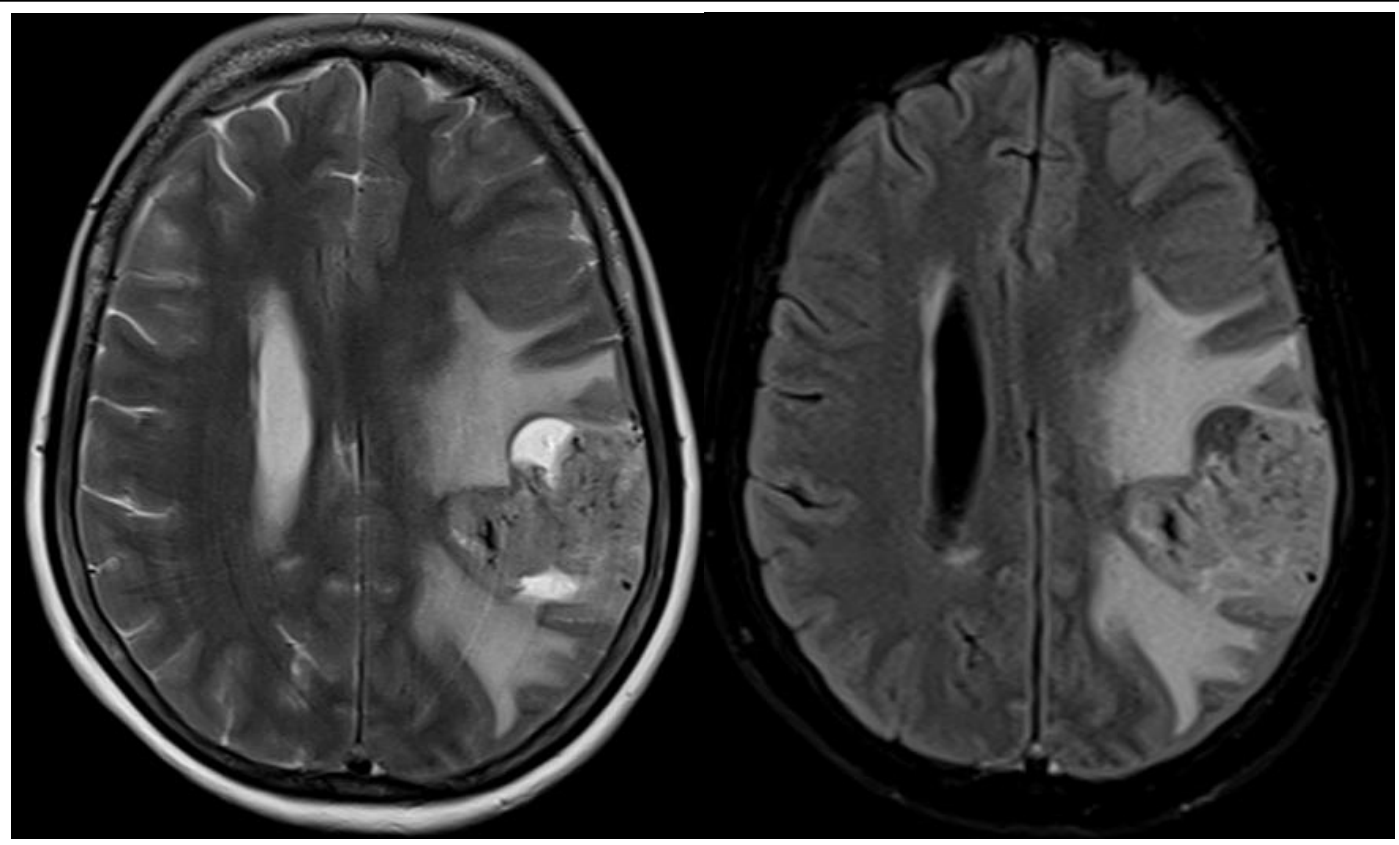

(C)Axial T2WI

(D)FLAIR

A case of atypical meningioma in a 45-year-old-female. Axial (A)T1W, Sagittal (B)T1W, Axial(C)T2WI and Axial(D)FLAIR images show heterogenous isointense left parietal lobe lesion with surrounding oedema.

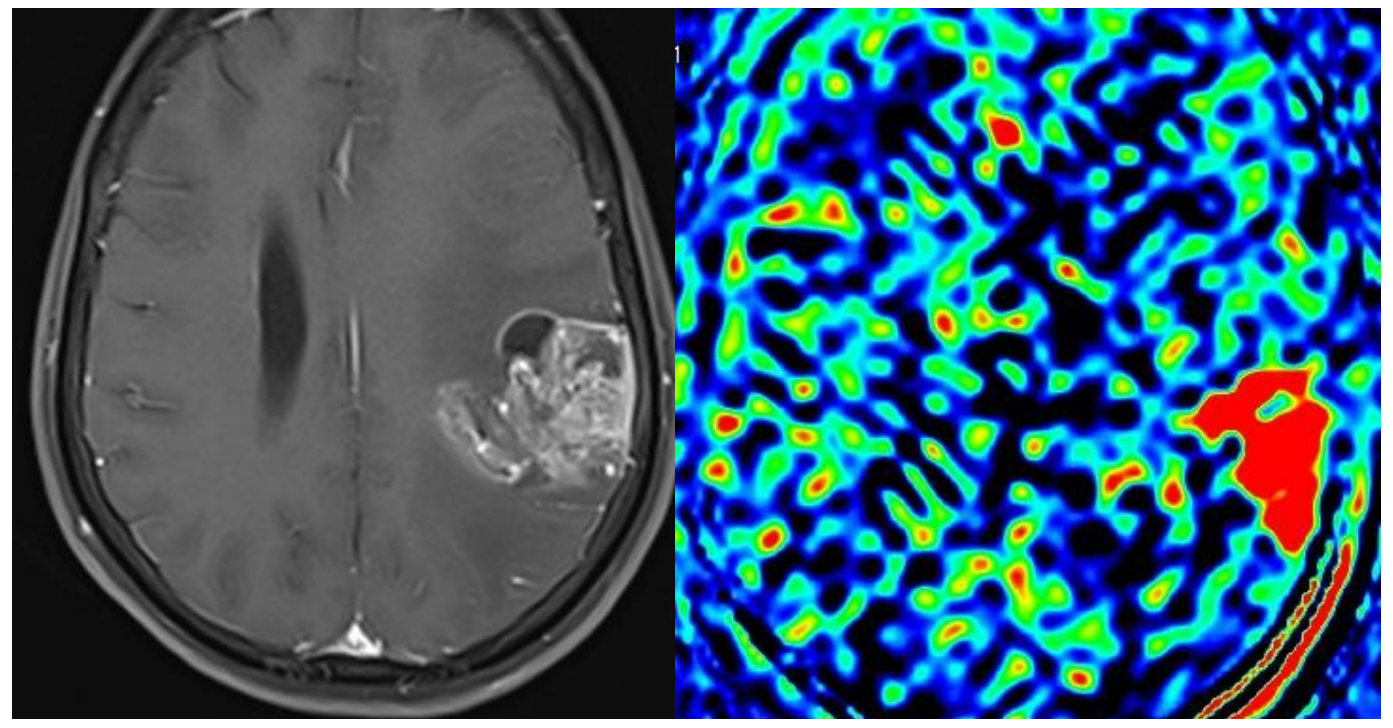

(E)Axial T1+C

(F)PWI

T1+C(E)show heterogenous enhancement with peritumoral cyst and PWI(F)show markedly increased perfusion. 


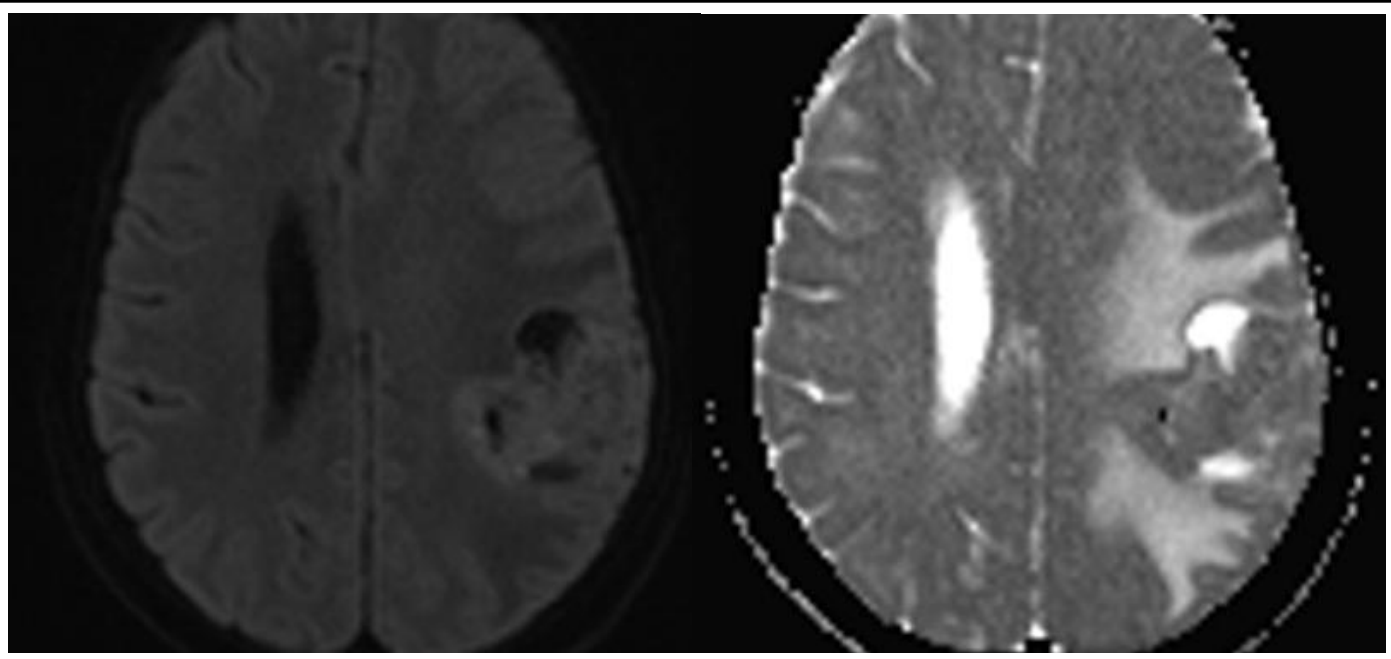

(G)DWI

(H)ADC

DWI(G)and $\operatorname{ADC}(H)$ show no restriction with necrotic foci

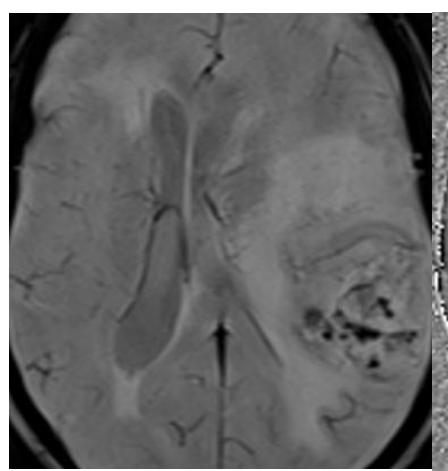

(I)SWI

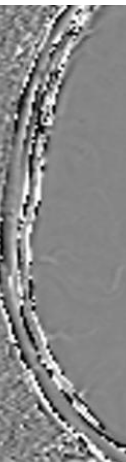

(3)

(J)Phase

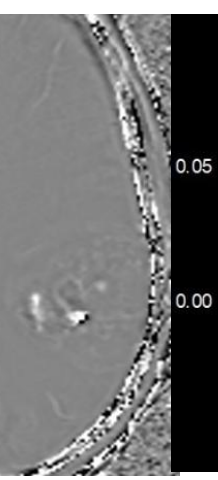

0.05

0.00

SWI (I)and Phase images(J)show calcific foci, MR spectrum(K)of the lesion shows increased Cho and decreased NAA, elevation of the alanine(yellow arrow).

Case 5: Abscess

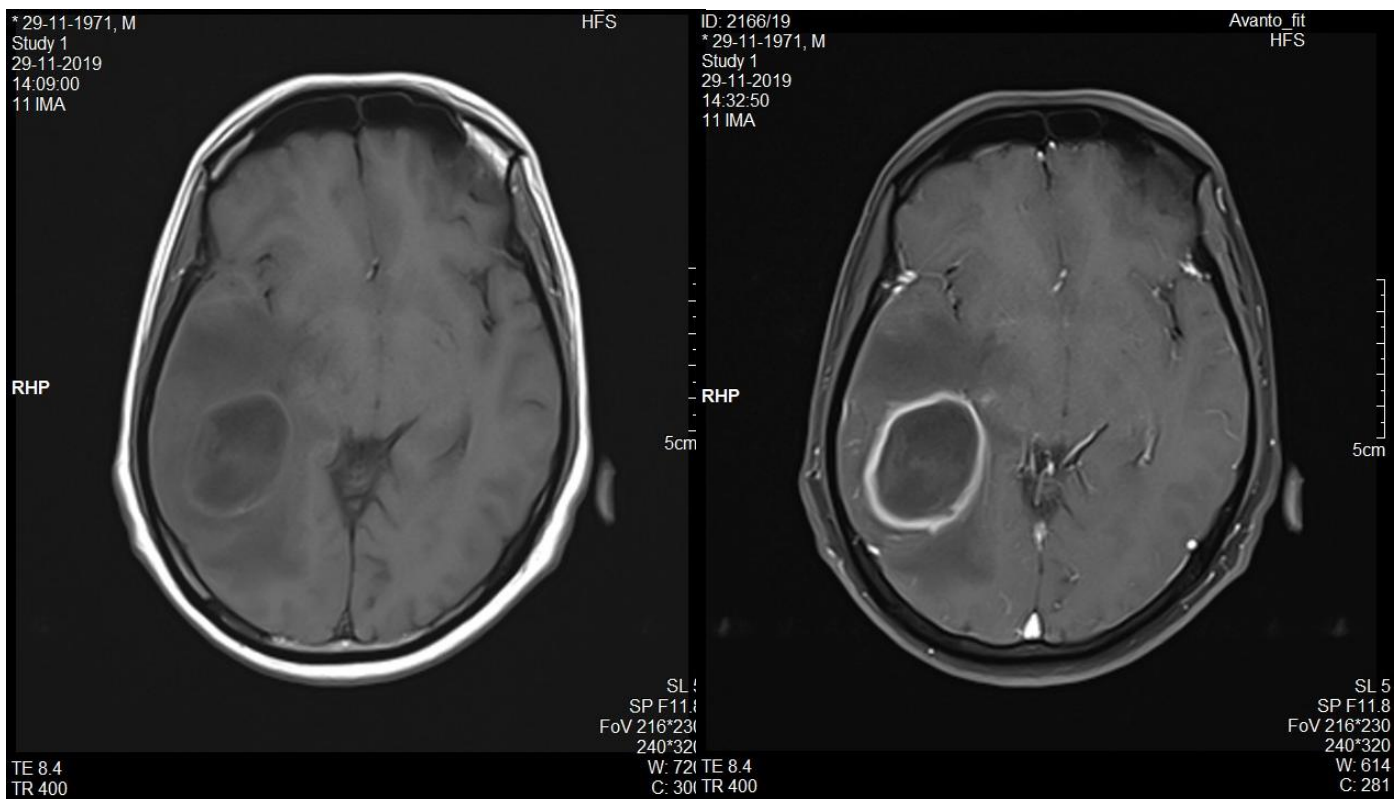

(A)Axial T1WI

(B)Axial T1+C 


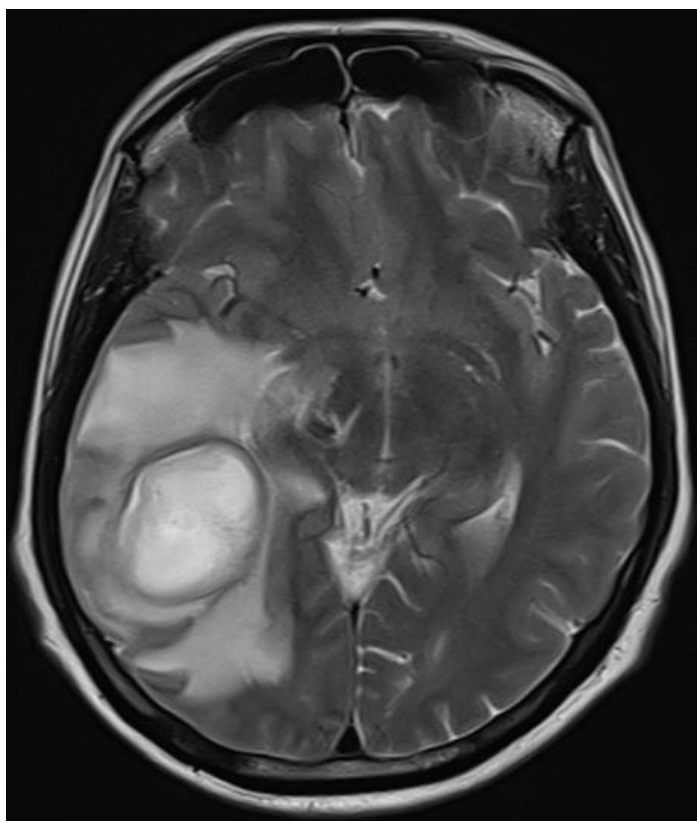

(C)Axial T2WI

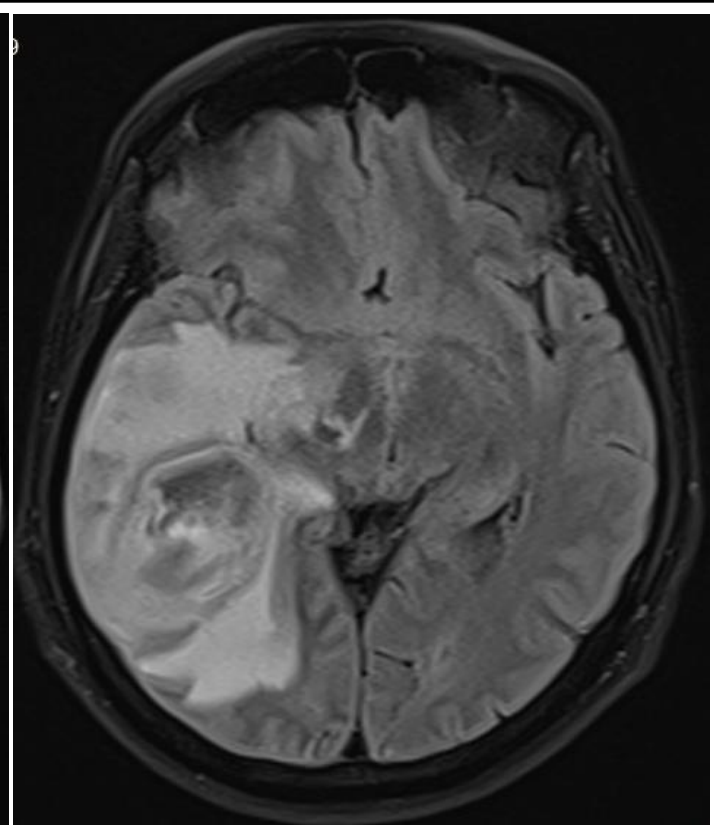

(D)Axial FLAIR

A case of cerebral abscess in a 48-year-old-male.(A)T1WI hypointense and(C)T2WI/(D)FLAIR hyperintense centre surrounded by an iso-intense wall showing ring enhancement on(B)T1W+C images in the right parietotemporal region.

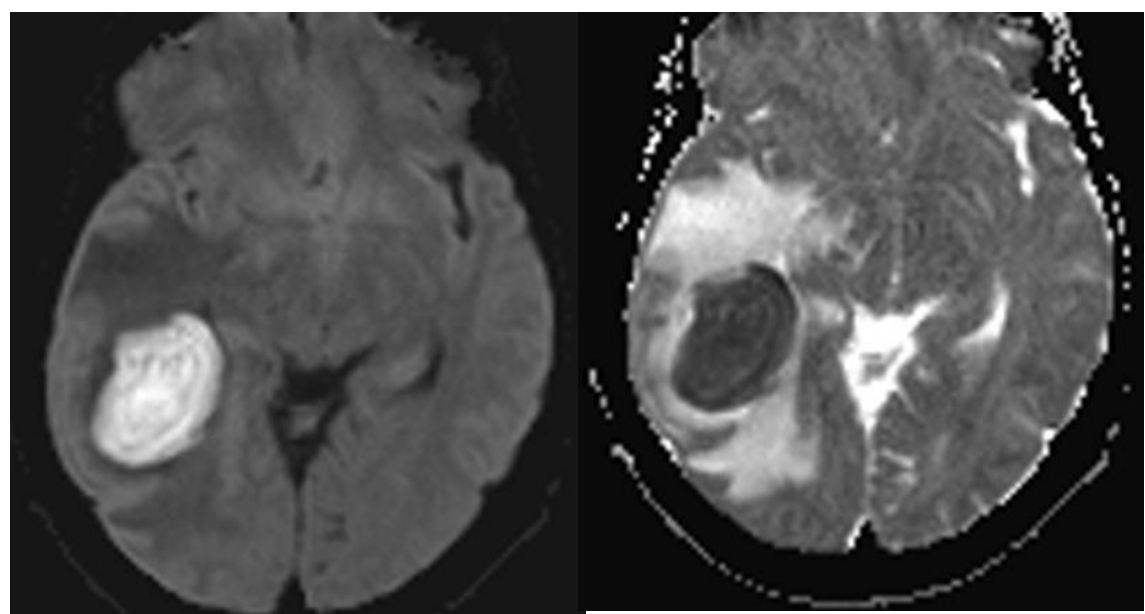

(E)DWI

(F)ADC

DWI $(E) \& A D C(F)$ show restricted diffusion in the centre of the lesion.

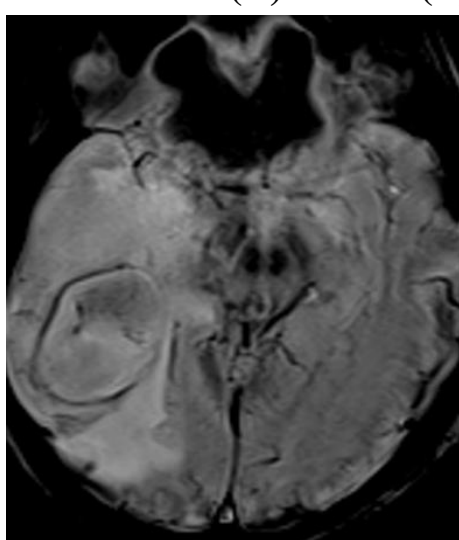

(G)SWI

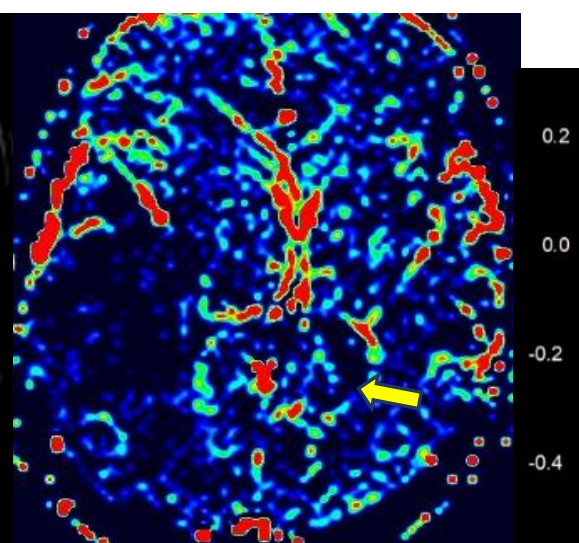

(H)PWI

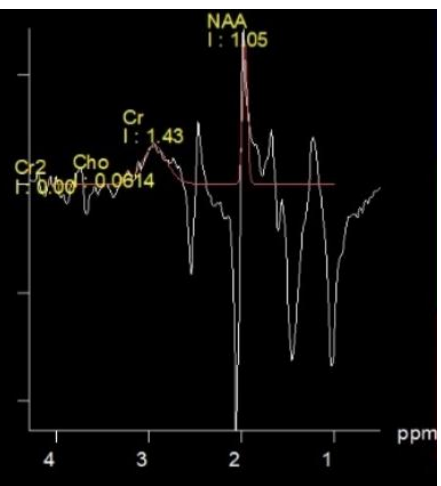

(I)MRS

SWI(G) shows dual ring sign; $(\mathrm{H}) \mathrm{rCBV}$ colour map shows markedly reduced perfusion within the lesion (yellow arrow), MRS(I)of the lesion shows decreased choline and increased lipid and lactate. 


\section{Discussion}

In comparison to our results, Tilgner $\mathbf{J}$ et $\mathbf{a l}(\mathbf{2 0 0 5})^{1}$ in one of the largest stereotactic brain biopsy series of 5000 patients reported that most common intraaxial brain masses were high-grade primary neoplasms $(36 \%)$, low-grade primary neoplasms (33\%), metastases(8\%), lymphoma $(5 \%)$, demyelinating and inflammatory conditions(3\%), infarcts(2\%), and abscesses(1\%). Some discrepancies in results were there may be due to the smaller sample size of our study and a smaller number of infective pathologies in developed countries. The similar finding also reported by Nícollas Nunes Rabelo et al $(2016)^{2}$ and Baghdady $A$ et $\mathbf{a l}(\mathbf{2 0 1 6})^{3}$ in their respective studies.

Most common pathology in the neoplastic group was metastases (34\% of neoplastic lesions) followed by $\operatorname{HGG}(22.22 \%)$, meningiomas(21\%). The mean age of neoplastic lesions was $50.27 \pm 15.82$ years and was more common in the male population with a $\mathrm{M}: \mathrm{F}$ ratio of $1.37: 1$. Similar results obtained by Tilgner J et al (2005) ${ }^{1}$ and Shan F Y et $\mathbf{a l}(\mathbf{2 0 1 7})^{4}$ in their respective studies. Most common pathology in the nonneoplastic group were abscess 6 cases (38\%) followed by tuberculoma and neurocysticercosis, each comprises $31.5 \%$ of non-neoplastic lesions. The mean age of non-neoplastic lesions was $42.25 \pm 12.86$ years and was more common in the male population. Similar results obtained in studies by Hourani R, et $\mathbf{a l}(\mathbf{2 0 0 8})^{5}$ and Nícollas Nunes Rabelo et $\mathbf{a l}(\mathbf{2 0 1 6})^{2}$ in their respective studies.

In our study, on DWI, neoplastic lesions had higher ADC values $(1.27 \pm 0.43)$ than the nonneoplastic lesions $(0.71 \pm 0.09)$. However, both groups of lesions showed decreased ADC in comparison to normal brain parenchyma. On PWI, neoplastic lesions had higher rCBV $(5.12 \pm 3.19)$ than the non-neoplastic lesions $(1.69 \pm 1.11)$. On MRS, NAA/Cr, Cho/NAA and $\mathrm{Cho} / \mathrm{Cr}$ ratios in neoplastic lesions were $1.22 \pm 0.69,3.01 \pm 1.86$ and $2.86 \pm 1.41$ respectively. While in non-neoplastic lesions NAA/Cr,
Cho/NAA and $\mathrm{Cho} / \mathrm{Cr}$ ratios were $0.97 \pm 0.47$, $2.43 \pm 1.10$ and $1.97 \pm 0.83$ respectively. Our study findings were comparable to studies done by Yamasaki et al (2005) $)^{6}$, Hourani $\mathbf{R}$, et al(2008) $)^{5}$ and Moller-Hartmann W(2002) ${ }^{7}$.

\section{Glioma}

In our study, on DWI low grade glioma has higher nADC values than the HGG. nADC values in the lesions were $1.07 \pm 0.43$ and $1.41 \pm 0.06$ in $\mathrm{HGG}$ and LGG respectively. Significantly, lower nADC values in perilesional oedema were present in the HGG in comparison to LGG and metastases suggesting tumour infiltration in HGG. On PWI for $\mathrm{HGG}$ and $\mathrm{LGG}$ rCBV values were $4.54 \pm 1.41$ and $1.33 \pm 0.27$, respectively. The mean $\mathrm{rCBV}$ ratio for glioblastomas and Grade II Astrocytoma were $5.36 \pm 0.68$ and $1.37 \pm 0.30$, respectively. On MRS, gliomas showed increased choline signals, decreased intensities of creatine and NAA compared to normal parenchyma. NAA/Cr, Cho/NAA and $\mathrm{Cho} / \mathrm{Cr}$ ratios were $0.33 \pm 0.11$, $5.75 \pm 1.15$ and $2.25 \pm 0.36$ in $\mathrm{HGG}$ and $0.56 \pm 0.08$, $3.43 \pm 0.55$ and $1.60 \pm 0.16$ in LGG respectively. HGG showed increase in lactate and in few glioblastoma lipid peaks were also present. Our study finding correlated with studies of $\mathbf{L u}$ et al (2004) $)^{8}$, Mehrabian et al $(2019)^{9}$, Hakyemez B et al (2006) ${ }^{10}$, Lai et al(2002) ${ }^{11}$ and Wang et al $(\mathbf{2 0 1 7})^{12}$.

\section{Metastases}

In our study, on DWI, nADC values in the metastatic lesions and perilesional oedema were $1.16 \pm 0.11$ and $1.82 \pm 0.08$. nADC values were decreased comparable to $\mathrm{HGG}$ but perilesional nADC values were not decreased as the HGG. On PWI the mean $\mathrm{rCBV}$ ratio for metastatic lesions was 5.19 \pm 1.30 . On MRS, NAA/Cr, Cho/NAA and $\mathrm{Cho} / \mathrm{Cr}$ ratios in metastatic lesions were $1.83 \pm 0.46,1.99 \pm 0.65$ and $1.97 \pm 0.83$ respectively and lipid/lactate peak were present in 12 cases $(80 \%)$. Similar to studies done by Hakyemez $B$ et $\mathbf{a l}(2006)^{10}$, Chatterjee $S$ et al(2009) ${ }^{13}$ and Poptani H(1995) $)^{14}$. 


\section{Meningiomas}

On DWI, nADC values in atypical and typical meningioma were $0.913 \pm 0.06$ and $1.125 \pm 0.08$ respectively. On PWI meningiomas were hypervascular and the mean $\mathrm{rCBV}$ ratio for typical and atypical meningiomas were 9.5 and 11.5 respectively. On MRS mean values of NAA/Cr, $\mathrm{Cho} / \mathrm{Cr}$ and $\mathrm{Cho} / \mathrm{NAA}$ for typical meningiomas were $1.58 \pm 0.27, \quad 1.96 \pm 0.85$ and $2.91 \pm 0.81$ respectively and for atypical meningiomas were $1.12 \pm 0.16,4.63 \pm 0.60$ and $5.16 \pm 1.23$ respectively. Our study well correlated with studies done by Nagar et al(2009) ${ }^{15}$, Hakyemez B et al(2006) ${ }^{10}$, Lin MC et $\operatorname{al}(2018)^{16}$ and Cho Y D et al $(2003)^{17}$. DNET

On PWI, DNET shows lower cerebral blood values than normal parenchyma with mean $\mathrm{rCBV}=0.88$. On MRS, no significant differences were detected in Cho/NAA, NAA/ $\mathrm{Cr}$ or $\mathrm{Cho} / \mathrm{Cr}$ ratios between DNET and normal brain. On DWI, lesions had higher ADC values (2.54 \pm 0.12$)$. Bulakbasi $\mathbf{N}$ et $\mathbf{a l ( 2 0 0 7 )})^{18}$ also reported no significant differences were detected on spectroscopy between DNET and normal brain, higher ADC values and lower cerebral blood values than normal parenchyma.

\section{Abscess}

On DW imaging, central restriction were present in all cases with mean nADC values in abscess were $0.65 \pm 0.05$. On PWI, mean $\mathrm{rCBV}$ ratio in the wall were $0.77 \pm 0.06$ and on MRS mean values of $\mathrm{NAA} / \mathrm{Cr}, \mathrm{Cho} / \mathrm{Cr}$ and $\mathrm{Cho} / \mathrm{NAA}$ for abscess were $1.47,2.53$ and 2.73 respectively with amino acid, succinate, and lactate peaks. Lipid peak was not present in any case. Our study well correlated with studies of Lai PH et al(2002) ${ }^{11}$, Chiang IC et al(2009) ${ }^{19}$ and Toh C et al(2014) ${ }^{20}$.

\section{Tuberculoma}

On DW imaging, variable degree of restriction were present in all cases with mean nADC values in tuberculoma were $1.33 \pm 0.51$. On PWI, mean rCBV ratio in the wall were $3.20 \pm 0.51$. On MRS mean values of NAA/Cr, $\mathrm{Cho} / \mathrm{Cr}$ and $\mathrm{Cho} / \mathrm{NAA}$ for tuberculomas were $0.59,3.50$ and 2.14 respectively. Tuberculomas had a high peak of lipids, more choline, less NAA and creatine. Our study well correlated with studies done by Vasudev S et al $(2007)^{21}$, Batra \& Tripathi et al $(2004)^{22}$, Ghosh RN et al (2018) ${ }^{23}$ andPretell $\mathbf{E}$ $\mathrm{J}$ et $\mathbf{a l}(\mathbf{2 0 0 5})^{24}$.

\section{Neurocysticercoses}

On DWI, variable degree of restriction was present in all cases with mean $\mathrm{nADC}$ values were $0.80 \pm 0.10$.On PWI, mean rCBV ratio in the wall were 1.27 \pm 1.2 . On MRS mean values of $\mathrm{NAA} / \mathrm{Cr}$, $\mathrm{Cho} / \mathrm{Cr}$ and $\mathrm{Cho} / \mathrm{NAA}$ were $0.74,1.23$ and 0.90 respectively. In two cases alanine (Peaks at 1.5 and 1.6), succinate(peak at $2.4 \mathrm{ppm}$ ) in 3 cases, lactate peak in all cases were present. Our study well correlated with the studies done by Santos G $\mathrm{T}$ et $\mathrm{al}(2013)^{25}$, Ghosh $\mathrm{RN}$ et $\mathrm{al}(2018)^{23}$ and Pretell E J et al(2005) $)^{24}$.

\section{Conclusion}

Although conventional MRI is, undoubtedly, the most sensitive modality available for the detection of brain tumours, it has low specificity. Intracranial masses may be life-threatening lesions that are refractory to even the most aggressive therapy or benign and require only occasional observation.

In practice, a tumour (e.g. glioma) is a lesion that should be treated aggressively, whereas a nonneoplastic lesion can be treated more conservatively. Misinterpretation may lead to a significant delay of adequate treatment of malignant tumours or may result in over-treatment of a tumour-like, benign lesion. Greater accuracy in imaging evaluation is important to plan appropriate management, especially when they occur at sites of high risk for biopsy.

In this regard, it should also be noted that biopsy only provides information about a portion of the neoplasm and not necessarily about the whole of it. A more accurate non-invasive approach implies extending the attainable information beyond the mere morphological parameters of contrast enhancement and vasogenic oedema observed on conventional imaging. 
The recent development of functional MRI sequences such as diffusion tensor imaging, perfusion-weighted imaging, magnetic resonance spectroscopy and susceptibility-weighted imaging facilitates the differentiation between tumour and tumour-like lesions. Integration of diagnostic information from above mentioned advanced MR imaging techniques not only can differentiate between neoplastic and non-neoplastic lesions with higher sensitivity and specificity but also help in evaluate different tumour types, predict tumour grade, improve the classification accuracy, serially and noninvasively monitor tumour progression, monitor the efficacy of therapy. So, these advanced imaging methods should be used routinely as a valuable non-invasive tool besides conventional MRI, whenever available, to reach a definitive final diagnosis in cases of brain tumours and tumour like lesions.

\section{Bibliography}

1. Tilgner, J., Herr, M., Ostertag, C. \& Volk, B. Validation of Intraoperative Diagnoses Using Smear Preparations from Stereotactic Brain Biopsies: Intraoperative versus Final Diagnosis-Influence of Clinical Factors. Neurosurgery 56, 257265 (2005).

2. Rabelo, N. et al. Differential Diagnosis between Neoplastic and Non-Neoplastic Brain Lesions in Radiology. Arq Bras Neurocir35, 045-061 (2016).

3. Baghdady, A., Maaly, M., El-wakeel, A. \& Mousa, W. The role of diffusion-weighted MRI in the evaluation and differentiation of space-occupying brain lesions. Menoufia Med J 29, 303 (2016).

4. Shan, F. Y. et al. Neoplasms of Central Nervous System: A Diagnostic Approach. Neoplasm (2018) doi:10.5772/intechopen.76294.

5. Hourani, R. et al. Can Proton MR Spectroscopic and Perfusion Imaging Differentiate Between Neoplastic and Nonneoplastic Brain Lesions in Adults?
American Journal of Neuroradiology 29, 366-372 (2008).

6. Yamasaki, F. et al. Apparent diffusion coefficient of human brain tumors at MR imaging. Radiology 235, 985-991 (2005).

7. Möller-Hartmann, W. et al. Clinical application of proton magnetic resonance spectroscopy in the diagnosis of intracranial mass lesions. Neuroradiology 44, 371-381 (2002).

8. Lu, S. et al. Diffusion-Tensor MR Imaging of Intracranial Neoplasia and Associated Peritumoral Edema: Introduction of the Tumor Infiltration Index. Radiology232, 221-228 (2004).

9. Mehrabian, H., Detsky, J., Soliman, H., Sahgal, A. \&Stanisz, G. J. Advanced Magnetic Resonance Imaging Techniques in Management of Brain Metastases. Front. Oncol. 9, 440 (2019).

10. Hakyemez, B. et al. Meningiomas with conventional MRI findings resembling intraaxial tumors: can perfusion-weighted MRI be helpful in differentiation? Neuroradiology48, 695-702 (2006).

11. Lai, P. H. et al. Brain Abscess and Necrotic Brain Tumor: Discrimination with Proton MR Spectroscopy and Diffusion-Weighted Imaging. 9 (2002).

12. Wang, Q. et al. Role of magnetic resonance spectroscopy to differentiate high-grade gliomas from metastases. Tumour Biol.39, 101042831771003 (2017).

13. Chatterjee, S. et al. Differentiation of tubercular infection and metastasis presenting as ring enhancing lesion by diffusion and perfusion magnetic resonance imaging. Journal of Neuroradiology37, 167-171 (2010).

14. Poptani, H. et al. Characterization of intracranial mass lesions with in vivo proton MR spectroscopy. AJNR Am J Neuroradiol16, 1593-1603 (1995). 
15. 15. Nagar, V. A. et al. DiffusionWeighted MR Imaging: Diagnosing Atypical or Malignant Meningiomas and Detecting Tumor Dedifferentiation. AJNR Am J Neuroradiol29, 1147-1152 (2008).

16. Lin, M.-C. et al. Preoperative grading of intracranial meningioma by magnetic resonance spectroscopy (1H-MRS). PLoS ONE13, e0207612 (2018).

17. Cho, Y.-D., Choi, G.-H., Lee, S.-P. \& Kim, J.-K. 1H-MRS metabolic patterns for distinguishing between meningiomas and other brain tumors. Magnetic Resonance Imaging 21, 663-672 (2003).

18. Bulakbasi, N., Kocaoglu, M., Sanal, T. H. \& Tayfun, C. Dysembryoplastic neuroepithelial tumors: proton $\mathrm{MR}$ spectroscopy, diffusion and perfusion characteristics. Neuroradiology49, 805812 (2007).

19. Chiang, I.-C. et al. Distinction between pyogenic brain abscess and necrotic brain tumour using 3-tesla MR spectroscopy, diffusion and perfusion imaging. BJR 82, 813-820 (2009).

20. Toh, C. H. et al. Differentiation of Brain Abscesses from Glioblastomas and Metastatic Brain Tumors: Comparisons of Diagnostic Performance of Dynamic Susceptibility Contrast-Enhanced Perfusion MR Imaging before and after Mathematic Contrast Leakage Correction. PLoS ONE9, e109172 (2014).

21. Vasudev, M. K., Jayakumar, P. N., Srikanth, S. G., Nagarajan, K. \& Mohanty, A. Quantitative magnetic resonance techniques in the evaluation of intracranial tuberculomas: Acta Radiologica (2016) doi:10.1080/02841850601067678.
22. Batra, A. \& Tripathi, R. P. Diffusion- weighted magnetic resonance imaging and magnetic resonance spectroscopy in the evaluation of focal cerebral tubercular lesions: Acta Radiologica (2016) doi:10.1080/02841850410001169.

23. Ghosh, R. N. et al. Perfusion magnetic resonance imaging in differentiation of neurocysticercosis and tuberculoma. Neuroradiology61, 257-263 (2019).

24. Pretell, E. J. et al. Differential Diagnosis Between Cerebral Tuberculosis and Neurocysticercosis by Magnetic Resonance Spectroscopy: Journal of Computer Assisted

25. Santos, G. T., Leite, C. C., Machado, L. R., McKinney, A. M. \&Lucato, L. T. Reduced Diffusion in Neurocysticercosis: Circumstances of Appearance and Possible Natural History Implications. AJNR Am J Neuroradiol 34, 310-316 (2013). 